Cochrane Database of Systematic Reviews

\title{
Stepping down the dose of inhaled corticosteroids for adults with asthma (Review)
}

Crossingham I, Evans DJW, Halcovitch NR, Marsden PA

Crossingham I, Evans DJW, Halcovitch NR, Marsden PA.

Stepping down the dose of inhaled corticosteroids for adults with asthma.

Cochrane Database of Systematic Reviews 2017, Issue 2. Art. No.: CD011802.

DOI: 10.1002/14651858.CD011802.pub2.

www.cochranelibrary.com 
TABLE OF CONTENTS

HEADER

ABSTRACT

PLAIN LANGUAGE SUMMARY

SUMMARY OF FINDINGS

BACKGROUND

OBJECTIVES

METHODS

RESULTS

Figure 1.

Figure 2.

Figure 3.

Figure 4.

Figure 5.

Figure 6.

Figure 7.

Figure 8.

Figure 9.

Figure 10.

Figure 11.

DISCUSSION

AUTHORS' CONCLUSIONS

ACKNOWLEDGEMENTS

REFERENCES

CHARACTERISTICS OF STUDIES

DATA AND ANALYSES

Analysis 1.1. Comparison 1 ICS dose reduction versus no change in ICS dose (no concomitant LABA), Outcome 1 Exacerbation requiring OCS.

Analysis 1.2. Comparison 1 ICS dose reduction versus no change in ICS dose (no concomitant LABA), Outcome 2 Asthma control.

Analysis 1.3. Comparison 1 ICS dose reduction versus no change in ICS dose (no concomitant LABA), Outcome 3 All-cause SAEs.

Analysis 1.4. Comparison 1 ICS dose reduction versus no change in ICS dose (no concomitant LABA), Outcome 4 Steroid-related AEs.

Analysis 1.5. Comparison 1 ICS dose reduction versus no change in ICS dose (no concomitant LABA), Outcome 5 Juniper AQLQ score (change from baseline).

Analysis 1.6. Comparison 1 ICS dose reduction versus no change in ICS dose (no concomitant LABA), Outcome 6 Lung function, PEFR morning (L/min).

Analysis 1.7. Comparison 1 ICS dose reduction versus no change in ICS dose (no concomitant LABA), Outcome 7 Lung function, FEV1 (L).

Analysis 2.1. Comparison 2 ICS dose reduction versus no change in ICS dose (concomitant LABA), Outcome 1 Exacerbation requiring OCS.

Analysis 2.2. Comparison 2 ICS dose reduction versus no change in ICS dose (concomitant LABA), Outcome 2 Asthma control (short asthma morbidity score), change from baseline.

Analysis 2.3. Comparison 2 ICS dose reduction versus no change in ICS dose (concomitant LABA), Outcome 3 Asthma control (Asthma Severity Questionnaire).

Analysis 2.4. Comparison 2 ICS dose reduction versus no change in ICS dose (concomitant LABA), Outcome 4 All-cause SAEs. .. Analysis 2.5. Comparison 2 ICS dose reduction versus no change in ICS dose (concomitant LABA), Outcome 5 EuroQoL score (change from baseline).

Analysis 2.6. Comparison 2 ICS dose reduction versus no change in ICS dose (concomitant LABA), Outcome 6 St. George's Respiratory Scale score (change from baseline).

Analysis 2.7. Comparison 2 ICS dose reduction versus no change in ICS dose (concomitant LABA), Outcome 7 Lung function, PEFR morning (L/min) (change from baseline). 
Analysis 2.8. Comparison 2 ICS dose reduction versus no change in ICS dose (concomitant LABA), Outcome 8 Lung function, reduction in FEV1 (\% predicted, change from baseline).

Analysis 2.9. Comparison 2 ICS dose reduction versus no change in ICS dose (concomitant LABA), Outcome 9 Exacerbation requiring hospitalisation.

Analysis 2.10. Comparison 2 ICS dose reduction versus no change in ICS dose (concomitant LABA), Outcome 10 Exacerbation requiring $E D$ visit.

Analysis 2.11. Comparison 2 ICS dose reduction versus no change in ICS dose (concomitant LABA), Outcome 11 Mortality. .... 
[Intervention Review]

\title{
Stepping down the dose of inhaled corticosteroids for adults with asthma
}

\author{
Iain Crossingham¹, David JW Evans², Nathan R Halcovitch³, Paul A Marsden 4
}

1East Lancashire Hospitals NHS Trust, Blackburn, UK. ${ }^{2}$ Lancaster Health Hub, Lancaster University, Lancaster, UK. ${ }^{3}$ Department of Chemistry, Lancaster University, Lancaster, UK. ${ }^{4}$ Lancashire Chest Centre, Lancashire Teaching Hospitals NHS Foundation Trust, Royal Preston Hospital, Preston, UK

Contact address: David JW Evans, Lancaster Health Hub, Lancaster University, Lancaster, LA1 4YG, UK. d.evans1@lancaster.ac.uk.

Editorial group: Cochrane Airways Group.

Publication status and date: New, published in Issue 2, 2017.

Citation: Crossingham I, Evans DJW, Halcovitch NR, Marsden PA. Stepping down the dose of inhaled corticosteroids for adults with asthma. Cochrane Database of Systematic Reviews 2017, Issue 2. Art. No.: CD011802. DOI: 10.1002/14651858.CD011802.pub2.

Copyright (c 2017 The Cochrane Collaboration. Published by John Wiley \& Sons, Ltd.

\section{A B S T R A C T}

\section{Background}

Asthma is a condition of the airways affecting more than 300 million adults and children worldwide. National and international guidelines recommend titrating up the dose of inhaled corticosteroids (ICS) to gain symptom control at the lowest possible dose because long-term use of higher doses of ICS carries a risk of systemic adverse events. For patients whose asthma symptoms are controlled on moderate or higher doses of ICS, it may be possible to reduce the dose of ICS without compromising symptom control.

\section{Objectives}

To evaluate the evidence for stepping down ICS treatment in adults with well-controlled asthma who are already receiving a moderate or high dose of ICS.

\section{Search methods}

We identified trials from the Specialised Register of the Cochrane Airways Group and conducted a search of ClinicalTrials.gov (www.ClinicalTrials.gov) and the World Health Organization (WHO) trials portal (www.who.int/ictrp/en/). We searched all databases from their inception with no restriction on language. We also searched the reference lists of included studies and relevant reviews. We performed the most recent search in July 2016.

\section{Selection criteria}

We included randomised controlled trials (RCTs) of at least 12 weeks' duration and excluded cross-over trials. We looked for studies of adults (aged $\geq 18$ years) whose asthma had been well controlled for a minimum of three months on at least a moderate dose of ICS. We excluded studies that enrolled participants with any other respiratory comorbidity.

We included trials comparing a reduction in the dose of ICS versus no change in the dose of ICS in people with well-controlled asthma who a) were not taking a concomitant long-acting beta agonist (LABA; comparison 1), and b) were taking a concomitant LABA (comparison 2).

\section{Data collection and analysis}

Two review authors independently screened the search results for included studies, extracted data on prespecified outcomes of interest and assessed the risk of bias of included studies; we resolved disagreements by discussion with a third review author. We analysed dichotomous data as odds ratios (ORs) using study participants as the unit of analysis and analysed continuous data as mean differences (MDs). We used a random-effects model. We rated all outcomes using the GRADE (Grades of Recommendation, Assessment, Development and Evaluation) system and presented results in 'Summary of findings' tables. 


\section{Main results}

We included six studies, which randomised a total of 1654 participants (ICS dose reduction, no concomitant LABA (comparison 1 ): $\mathrm{n}=892$ participants, three RCTs; ICS dose reduction, concomitant LABA (comparison 2): $\mathrm{n}=762$ participants, three RCTs). All included studies were RCTs with a parallel design that compared a fixed dose of ICS versus a $50 \%$ to $60 \%$ reduction in the dose of ICS in adult participants with well-controlled asthma. The duration of the treatment period ranged from 12 to 52 weeks (mean duration 21 weeks; median duration 14 weeks). Two studies were performed in the setting of primary care, two were performed in the secondary care setting and two reported no information on setting.

Meta-analysis was hampered by the small number of studies contributing to each comparison, combined with heterogeneity among outcomes reported in the included studies. We found the quality of synthesised evidence to be low or very low for most outcomes considered because of a risk of bias (principally, selective reporting), imprecision and indirectness. Although we found no statistically significant or clinically relevant differences between groups with respect to any of the primary or secondary outcomes considered in this review, the data were insufficient to rule out benefit or harm.

\section{Authors' conclusions}

The strength of the evidence is not sufficient to determine whether stepping down the dose of ICS is of net benefit (in terms of fewer adverse effects) or harm (in terms of reduced effectiveness of treatment) for adult patients with well-controlled asthma. A small number of relevant studies and varied outcome measures limited the number of meta-analyses that we could perform. Additional well-designed RCTs of longer duration are needed to inform clinical practice regarding use of a 'stepping down ICS' strategy for patients with well-controlled asthma.

\section{PLAIN LANGUAGE SUMMARY}

\section{Stepping down the dose of inhaled corticosteroids for adults with asthma}

\section{Background}

Asthma is a condition of the airways affecting more than 300 million adults and children worldwide. National and international guidelines recommend increasing the dose of inhaled corticosteroids (ICS) in steps to gain control of symptoms at the lowest possible dose because long-term use of higher doses of ICS carries a risk of side effects. For patients whose asthma symptoms are controlled on moderate or higher doses of ICS, it may be possible to reduce the dose of ICS (step down) without losing control of asthma symptoms.

\section{Review question}

We searched for studies (minimum length 12 weeks) in people with well-controlled asthma that compared the effect of reducing the dose of ICS versus maintaining the dose of ICS. Studies had to include adults aged 18 years or older whose asthma was well controlled on a medium dose of ICS for a minimum of three months. We were also interested in determining whether taking another type of inhaled asthma medication (long-acting beta agonists - LABAs) would influence the results. Two review authors screened the search results independently of each other and determined which studies were relevant for inclusion in this review. The relevant information from these studies was also added to this review by two review authors independently.

\section{Results}

We found six studies that were relevant to our review. Overall, we found no differences between groups (reduced ICS dose vs maintained ICS dose) in terms of asthma attacks, asthma control, quality of life or side effects. Taking or not taking LABA at the same time did not appear to affect the results. However, we assessed the quality of the evidence as low or very low because of the low number of studies found and problems with how the studies were reported. This means that we cannot be certain of our findings; additional studies are needed to explore this topic.

\section{Conclusions}

In conclusion, current evidence is not good enough to show whether patients can reduce their ICS dose without losing control of their asthma. It is also not clear whether stepping down the dose of ICS would reduce the occurrence of side effects. Additional studies are needed to answer this question. 
SUMMARY OF FINDINGS

Summary of findings for the main comparison. ICS dose reduction compared with no change in ICS dose (no concomitant LABA) for adults with asthma

ICS dose reduction compared with no change in ICS dose (no concomitant LABA) for adults with asthma

Patient or population: adults with asthma

Setting: primary care and specialist centres

Intervention: ICS dose reduction

Comparison: no change in ICS dose (no concomitant LABA)

\begin{tabular}{|c|c|c|c|c|c|c|}
\hline \multirow[t]{2}{*}{ Outcomes } & \multicolumn{2}{|c|}{ Anticipated absolute effects ${ }^{\star}(95 \% \mathrm{CI})$} & \multirow{2}{*}{$\begin{array}{l}\text { Relative effect } \\
(95 \% \mathrm{CI})\end{array}$} & \multirow{2}{*}{$\begin{array}{l}\text { Number of par- } \\
\text { ticipants } \\
\text { (studies) }\end{array}$} & \multirow{2}{*}{$\begin{array}{l}\text { Quality of the } \\
\text { evidence } \\
\text { (GRADE) }\end{array}$} & \multirow[t]{2}{*}{ Comments } \\
\hline & $\begin{array}{l}\text { Risk with no change } \\
\text { in ICS dose (no con- } \\
\text { comitant LABA) }\end{array}$ & $\begin{array}{l}\text { Risk with ICS } \\
\text { dose reduction }\end{array}$ & & & & \\
\hline $\begin{array}{l}\text { Exacerbation requiring OCS } \\
\text { Follow-up: range } 10 \text { weeks to } \\
12 \text { weeks }\end{array}$ & 8 per 1000 & $\begin{array}{l}14 \text { per } 1000 \\
(1 \text { to } 140)\end{array}$ & $\begin{array}{l}\text { OR } 1.86 \\
\text { (0.16 to } 21.09)\end{array}$ & $\begin{array}{l}261 \\
(2 \text { RCTs })\end{array}$ & $\begin{array}{l}\oplus \ominus \ominus \ominus \\
\text { Very lowa }\end{array}$ & $\begin{array}{l}\text { No clear benefit or harm of stepping } \\
\text { down the dose of ICS (very low-qual- } \\
\text { ity evidence) }\end{array}$ \\
\hline $\begin{array}{l}\text { Asthma control } \\
\text { assessed by: Asthma Symp- } \\
\text { tom Scale from: } 0 \text { (no symp- } \\
\text { toms) to } 5 \text { (severe symptoms) } \\
\text { Follow-up: } 10 \text { weeks }\end{array}$ & $\begin{array}{l}\text { Mean asthma con- } \\
\text { trol score in the no } \\
\text { change in ICS dose } \\
\text { group was } 1.79 .\end{array}$ & $\begin{array}{l}\text { MD } 0.22 \text { lower } \\
\text { (1.05 lower to } \\
0.61 \text { higher) }\end{array}$ & - & $\begin{array}{l}150 \\
(1 \mathrm{RCT})\end{array}$ & $\begin{array}{l}\oplus \oplus \oplus \ominus \\
\text { Lowb }^{b}\end{array}$ & $\begin{array}{l}\text { No clear benefit or harm of stepping } \\
\text { down the dose of ICS (low-quality ev- } \\
\text { idence) }\end{array}$ \\
\hline $\begin{array}{l}\text { All-cause SAEs } \\
\text { Follow-up: mean } 12 \text { weeks }\end{array}$ & 8 per 1000 & $\begin{array}{l}9 \text { per } 1000 \\
(2 \text { to } 45)\end{array}$ & $\begin{array}{l}\text { OR } 1.24 \\
(0.25 \text { to } 6.25)\end{array}$ & $\begin{array}{l}742 \\
(2 \mathrm{RCTs})\end{array}$ & $\begin{array}{l}\oplus \oplus \ominus \ominus \\
\text { Lowc }\end{array}$ & $\begin{array}{l}\text { No clear benefit or harm of stepping } \\
\text { down the dose of ICS (low-quality ev- } \\
\text { idence) }\end{array}$ \\
\hline $\begin{array}{l}\text { Steroid-related AEs } \\
\text { Follow-up: range } 10 \text { weeks to } \\
12 \text { weeks }\end{array}$ & 31 per 1000 & $\begin{array}{l}23 \text { per } 1000 \\
(5 \text { to } 100)\end{array}$ & $\begin{array}{l}\text { OR } 0.76 \\
(0.16 \text { to } 3.54)\end{array}$ & $\begin{array}{l}261 \\
\text { (2 RCTs) }\end{array}$ & $\begin{array}{l}\oplus \ominus \ominus \ominus \\
\text { Very lowd }\end{array}$ & $\begin{array}{l}\text { No clear benefit or harm of stepping } \\
\text { down the dose of ICS (very low-qual- } \\
\text { ity evidence) }\end{array}$ \\
\hline $\begin{array}{l}\text { Health-related quality of life } \\
\text { (change from baseline) } \\
\text { assessed by: AQLQ } \\
\text { Follow-up: } 12 \text { weeks }\end{array}$ & $\begin{array}{l}\text { Mean change from } \\
\text { baseline in health-re- } \\
\text { lated quality of life } \\
\text { for the no change in } \\
\text { ICS dose group was } \\
0.02 \text {. }\end{array}$ & $\begin{array}{l}\text { MD } 0.21 \text { lower } \\
\text { (0.33 lower to } \\
0.09 \text { lower) }\end{array}$ & - & $\begin{array}{l}554 \\
(1 \mathrm{RCT})\end{array}$ & $\begin{array}{l}\oplus \ominus \Theta \Theta \\
\text { Very lowe }\end{array}$ & $\begin{array}{l}\text { No clear benefit or harm of stepping } \\
\text { down the dose of ICS (very low-quali- } \\
\text { ty evidence); MCID is } 0.5 \text { for AQLQ }\end{array}$ \\
\hline
\end{tabular}


Lung function, $\mathrm{FEV}_{1}(\mathrm{~L})$ assessed by: spirometry Follow-up: range 10 weeks to 12 weeks

\section{Mean $\mathrm{FEV}_{1}$ in the no}

change in ICS dose

group was 3.15 litres.
MD 0.02 litres

lower

(0.12 lower to 0.08 higher) $\oplus \oplus \ominus \ominus$

Low $^{f}$
No clear benefit or harm of stepping down the dose of ICS (low-quality evidence)

Exacerbations requiring hospitalisation - not reported

${ }^{*}$ Risk in the intervention group (and its 95\% confidence interval) is based on assumed risk in the comparison group and the relative effect of the intervention (and its 95\% $\mathrm{Cl})$

aThe quality of the evidence was downgraded once for indirectness (included studies were performed at specialist centres) and twice for imprecision (no events reported by Magnussen 2000; confidence intervals include null effect and appreciable benefit or harm).

bThe quality of the evidence was downgraded once for risk of bias (selective reporting) and once for indirectness (single study representative of one setting and drug regimen).

CThe quality of the evidence was downgraded once for risk of bias (selective reporting) and once for imprecision (confidence intervals include null effect and appreciable benefit or harm).

dThe quality of the evidence was downgraded once for risk of bias (selective reporting), once for indirectness (representative of specialist centres) and once for imprecision (confidence intervals include null effect and appreciable benefit or harm).

eThe quality of the evidence was downgraded twice for risk of bias (selective reporting and lack of blinding (subjective outcome)) and once for indirectness (single study representative of one setting and drug regimen).

TThe quality of the evidence was downgraded once for risk of bias (selective reporting) and once for imprecision (confidence intervals include null effect and appreciable benefit or harm).

$\mathrm{AE}$, adverse event; AQLQ, Asthma Quality of Life Questionnaire; $\mathrm{Cl}$, confidence interval; $\mathrm{FEV}_{1}$, forced expiratory volume in one second; GRADE, Grades of Recommendation, Assessment, Development and Evaluation; ICS, inhaled corticosteroid; LABA, long-acting beta agonist; MCID, minimum clinically important difference; MD, mean difference; OCS, oral corticosteroid; OR, odds ratio; $\mathrm{RCT}$, randomised controlled trial; $\mathrm{RR}$, risk ratio; SAE, serious adverse event.

\section{GRADE Working Group grades of evidence}

High quality: We are very confident that the true effect lies close to the estimate of effect.

Moderate quality: We are moderately confident in the effect estimate: The true effect is likely to be close to the estimate of effect but may be substantially different.

Low quality: Our confidence in the effect estimate is limited: The true effect may be substantially different from the estimate of effect.

Very low quality: We have very little confidence in the effect estimate: The true effect is likely to be substantially different from the estimate of effect.

\section{Summary of findings 2. ICS dose reduction compared with no change in ICS dose (concomitant LABA) for adults with asthma}

ICS dose reduction compared with no change in ICS dose (concomitant LABA) for adults with asthma

Patient or population: adults with asthma 


\begin{tabular}{|c|c|c|c|c|c|c|}
\hline $\begin{array}{l}\text { Intervention: ICS dose reducti } \\
\text { Comparison: no change in ICS }\end{array}$ & $\begin{array}{l}\text { n } \\
\text { lose (concomitant }\end{array}$ & ABA) & & & & \\
\hline \multirow[t]{2}{*}{ Outcomes } & \multicolumn{2}{|c|}{$\begin{array}{l}\text { Anticipated absolute effects* } \\
(95 \% \mathrm{Cl})\end{array}$} & \multirow[t]{2}{*}{$\begin{array}{l}\text { Relative effect } \\
(95 \% \mathrm{CI})\end{array}$} & \multirow{2}{*}{$\begin{array}{l}\text { Number of par- } \\
\text { ticipants } \\
\text { (studies) }\end{array}$} & \multirow{2}{*}{$\begin{array}{l}\text { Quality of the } \\
\text { evidence } \\
\text { (GRADE) }\end{array}$} & \multirow[t]{2}{*}{ Comments } \\
\hline & $\begin{array}{l}\text { Risk with no } \\
\text { change in ICS } \\
\text { dose (concomi- } \\
\text { tant LABA) }\end{array}$ & $\begin{array}{l}\text { Risk with ICS } \\
\text { dose reduction }\end{array}$ & & & & \\
\hline $\begin{array}{l}\text { Exacerbation requiring OCS } \\
\text { Follow-up: range } 4 \text { months to } \\
12 \text { months }\end{array}$ & 148 per 1000 & $\begin{array}{l}186 \text { per } 1000 \\
(125 \text { to } 266)\end{array}$ & $\begin{array}{l}\text { OR } 1.31 \\
\text { (0.82 to } 2.08)\end{array}$ & $\begin{array}{l}569 \\
(2 \mathrm{RCTs})\end{array}$ & $\begin{array}{l}\oplus \oplus \odot \odot \\
\text { Lowa }\end{array}$ & $\begin{array}{l}\text { No clear benefit or harm of stepping down } \\
\text { the dose of ICS with respect to exacerba- } \\
\text { tions requiring OCS (low-quality evidence) }\end{array}$ \\
\hline $\begin{array}{l}\text { Asthma control (short asthma } \\
\text { morbidity score) } \\
\text { Follow-up: } 12 \text { months }\end{array}$ & $\begin{array}{l}\text { Mean asthma } \\
\text { control score } \\
\text { was } 1.43 .\end{array}$ & $\begin{array}{l}\text { MD } 0.16 \text { higher } \\
\text { (0.34 lower to } \\
0.66 \text { higher) }\end{array}$ & - & $\begin{array}{l}242 \\
(1 \mathrm{RCT})\end{array}$ & $\begin{array}{l}\oplus \oplus \ominus \ominus \\
\text { Lowb }\end{array}$ & $\begin{array}{l}\text { No clear benefit or harm of stepping down } \\
\text { the dose of ICS with respect to asthma } \\
\text { control (low-quality evidence) }\end{array}$ \\
\hline $\begin{array}{l}\text { All-cause SAEs } \\
\text { Follow-up: range } 4 \text { months to } \\
12 \text { months }\end{array}$ & 35 per 1000 & $\begin{array}{l}22 \text { per } 1000 \\
(4 \text { to } 109)\end{array}$ & $\begin{array}{l}\text { OR } 0.60 \\
\text { (0.11 to } 3.33)\end{array}$ & $\begin{array}{l}569 \\
(2 \mathrm{RCTs})\end{array}$ & $\begin{array}{l}\oplus \oplus \odot \odot \\
\text { Lowa }\end{array}$ & $\begin{array}{l}\text { No clear benefit or harm of stepping down } \\
\text { the dose of ICS with respect to all-cause } \\
\text { SAEs (low-quality evidence) }\end{array}$ \\
\hline $\begin{array}{l}\text { Steroid-related AEs - not re- } \\
\text { ported }\end{array}$ & - & - & - & - & - & \\
\hline $\begin{array}{l}\text { St. George's Respiratory Scale } \\
\text { score (change from baseline) } \\
\text { Follow-up: } 12 \text { months } \\
\text { Score } 0-100.100=\text { greatest } \\
\text { impact of chest disease on } \\
\text { life; MCID is } 4 \text { units. }\end{array}$ & $\begin{array}{l}\text { Mean change } \\
\text { from baseline } \\
\text { in HRQoL score } \\
\text { was 7.4.c }\end{array}$ & $\begin{array}{l}\text { MD } 0.13 \text { higher } \\
\text { (2.8 lower to } \\
3.06 \text { higher) }\end{array}$ & - & $\begin{array}{l}229 \\
(1 \mathrm{RCT})\end{array}$ & $\begin{array}{l}\oplus \oplus \ominus \ominus \\
\text { Lowb }\end{array}$ & $\begin{array}{l}\text { No clear benefit or harm of stepping down } \\
\text { the dose of ICS with respect to HRQOL } \\
\text { (low-quality evidence) }\end{array}$ \\
\hline $\begin{array}{l}\text { Exacerbation requiring hospi- } \\
\text { talisation } \\
\text { Follow-up: range } 4 \text { months to } \\
12 \text { months }\end{array}$ & 4 per 1000 & $\begin{array}{l}14 \text { per } 1000 \\
(2 \text { to } 116)\end{array}$ & $\begin{array}{l}\text { OR } 4.06 \\
(0.45 \text { to } 36.86)\end{array}$ & $\begin{array}{l}569 \\
(2 \mathrm{RCTs})\end{array}$ & $\begin{array}{l}\oplus \oplus \ominus \ominus \\
\text { Lowd }\end{array}$ & $\begin{array}{l}\text { No clear benefit or harm of stepping down } \\
\text { the dose of ICS with respect to exacerba- } \\
\text { tions requiring hospitalisation (low-quali- } \\
\text { ty evidence) }\end{array}$ \\
\hline $\begin{array}{l}\text { Lung function, reduction in } \\
\mathrm{FEV}_{1} \text { (\% predicted, change } \\
\text { from baseline) } \\
\text { Follow-up: } 3 \text { months }\end{array}$ & $\begin{array}{l}\text { Mean change } \\
\text { from baseline } \\
\text { in } \% \text { predict- } \\
\text { ed } \mathrm{FEV}_{1} \text { was } \\
-0.75 \% \text {. }\end{array}$ & $\begin{array}{l}\text { MD } 2.45 \text { lower } \\
\text { (8.88 lower to } \\
\text { 3.98 higher) }\end{array}$ & - & $\begin{array}{l}14 \\
(1 \mathrm{RCT})\end{array}$ & $\begin{array}{l}\oplus \ominus \Theta \odot \\
\text { Very lowe }\end{array}$ & $\begin{array}{l}\text { No clear benefit or harm of stepping down } \\
\text { the dose of ICS with respect to lung func- } \\
\text { tion (very low-quality evidence) }\end{array}$ \\
\hline
\end{tabular}


${ }^{*}$ Risk in the intervention group (and its 95\% confidence interval) is based on assumed risk in the comparison group and the relative effect of the intervention (and its 95\% $\mathrm{Cl}$.

aThe quality of the evidence was downgraded once for risk of bias (selective reporting) and once for imprecision (confidence intervals include null effect and appreciable benefit or harm).

bThe quality of the evidence was downgraded once for risk of bias (selective reporting) and once for indirectness (single study representative of one setting and drug regimen).

cNote that study authors reported the change to the lowest SGRQ score during follow-up.

dThe quality of the evidence was downgraded once for risk of bias (selective reporting) and once for imprecision (confidence intervals include null effect and appreciable benefit or harm).

eThe quality of the evidence was downgraded once for risk of bias (selective reporting), once for indirectness (single study representative of one setting or drug regimen) and once for imprecision (wide $\mathrm{Cl}$ ).

$\mathrm{AE}$, adverse event; $\mathrm{Cl}$, confidence interval; $\mathrm{FEV}_{1}$, forced expiratory volume in one second; GRADE, Grades of Recommendation, Assessment, Development and Evaluation HRQoL, health-related quality of life; ICS, inhaled corticosteroid; LABA, long-acting beta agonist; MCID, minimum clinically important difference; MD, mean difference; OCS, oral corticosteroid; OR, odds ratio; RCT, randomised controlled trial; RR, risk ratio; SAE, serious adverse event.

\section{GRADE Working Group grades of evidence}

High quality: We are very confident that the true effect lies close to that of the estimate of the effect

Moderate quality: We are moderately confident in the effect estimate: The true effect is likely to be close to the estimate of the effect, but there is a possibility that it is substantially different

Low quality: Our confidence in the effect estimate is limited: The true effect may be substantially different from the estimate of the effect

Very low quality: We have very little confidence in the effect estimate: The true effect is likely to be substantially different from the estimate of effect 


\section{B A C K G R O U N D}

\section{Description of the condition}

Asthma is a condition of the airways affecting adults and children. The number of diagnoses worldwide is estimated at more than 300 million (Global Asthma Network 2014; Partridge 2006). During an asthma attack (exacerbation), narrowing of the airways and excess mucus production occurs, causing symptoms of chest tightness, wheezing and breathlessness. Lung function tests typically show airflow obstruction with a low peak expiratory flow rate (PEFR), low forced expiratory volume in one second $\left(\mathrm{FEV}_{1}\right)$ and a low $\mathrm{FEV}_{1} /$ forced vital capacity (FVC) ratio (SIGN/BTS 2016). Lung function abnormalities improve and function may return to normal with treatment. Variability in measures of airflow is the hallmark of asthma.

Exacerbations of asthma can be triggered by environmental stimuli. In immunoglobulin E (IgE)-mediated asthma (which may account for half of asthma cases) (Pearce 1999), indoor inhaled allergens such as house dust mite, cat and dog are often implicated (Custovic 2012). Other recognised environmental stimuli include air pollutants such as ozone and fine particulates, active and passive exposure to tobacco smoke (Xepapadaki 2009), industrial chemicals such as phthalates (Jaakkola 2008), isocyanates (Fisseler-Eckhoff 2011), viral infections and cold air.

\section{Description of the intervention}

Acute episodes of asthma are treated with reliever therapy, usually a short-acting beta ${ }_{2}$-agonist (SABA). Inhaled corticosteroids (ICS) are used widely as first-line therapy for patients with asthma that is uncontrolled on reliever therapy alone (SIGN/BTS 2016). Inhaled corticosteroids, which effectively relieve symptoms and prevent asthma exacerbations (Adams 2005; Adams 2008), are preferable to treatment by the oral route, as they lead to lower systemic absorption and fewer side effects. However, economic and social factors may contribute to non-compliance with inhaler-based therapies in some low- and middle-income countries (GINA 2016). A variety of devices are available for delivery of ICS at differing doses and particle sizes. Generally, ICS are taken twice daily, although some newer preparations are taken once daily. For patients with persistent asthma, ICS are often taken alongside a long-acting beta $_{2}$ agonist (LABA), sometimes via a combination inhaler. ICS should be commenced at a dose appropriate to disease severity and control. National and international guidelines recommend titrating up the dose of ICS to gain symptom control at the lowest possible dose. Long-term use of higher doses of ICS carries risk of systemic adverse events (i.e. side effects caused by the action of the steroid at sites other than the intended target - the airways) (Lipworth 1999); however, lower doses of up to $800 \mathrm{mcg}$ per day of beclomethasone dipropionate are considered tolerable (SIGN/ BTS 2016). For patients whose asthma symptoms are controlled on moderate or higher doses of ICS, it may be possible to reduce the dose of ICS without compromising symptom control (Hawkins 2003).

\section{How the intervention might work}

ICS offer effective treatment for asthma owing to their antiinflammatory and decongestive effects on bronchial airways (Tse 1984). LABA function by decreasing bronchial hyperreactivity to physical and chemical stimuli and by relaxing bronchial smooth muscle (Lipworth 1992). Guidelines for asthma treatment focus on achieving, then maintaining, control while balancing the risks associated with long-term medication (Bateman 2008). Once asthma control is achieved (e.g. as per GINA 2016 criteria), guidelines recommend 'stepping down' treatment to the lowest possible dose of ICS (SIGN/BTS 2016). These recommendations are based on known risks of systemic adverse effects (e.g. loss of bone density in adults, growth retardation in children) associated with long-term use of high-dose ICS (Colice 2006; Lipworth 1999; SIGN/ BTS 2016).

\section{Why it is important to do this review}

Patients with persistent asthma are generally treated with a high dose of ICS or with a combination of ICS and LABA (Ducharme 2010). Two separate Cochrane reviews (Ahmad 2015; Kew 2015) have synthesised the evidence for removing the LABA from the ICS/LABA combination when treating children and adults with asthma. Stepping down the dose of ICS may reduce the likelihood of unwanted side effects, particularly the systemic side effects of steroid use (Colice 2006; SIGN/BTS 2016). Indeed, current British Thoracic Society (BTS)/Scottish Intercollegiate Guidelines Network (SIGN) guidelines recommend that ICS should be titrated to the lowest possible dose at which effective asthma control is maintained (SIGN/BTS 2016). However, debate continues regarding the best protocol for stepping down ICS treatment, particularly with respect to the lowest acceptable dose of ICS and the rate of downtitration (Rogers 2012). Therefore, synthesis of the evidence for 'stepping down ICS therapy' is important. Finally, ICS are among the most widely prescribed repeat medications and thus account for a substantial proportion of drug spending in the United Kingdom and in other countries (NHS 2013). Any strategy to reduce the use of ICS may thus represent an important cost-saving measure.

\section{O B J E C T IVES}

To evaluate the evidence for stepping down ICS treatment in adults with well-controlled asthma who are already receiving a moderate or high dose of ICS.

\section{METHODS}

\section{Criteria for considering studies for this review Types of studies}

We included parallel-group randomised controlled trials (RCTs) of at least 12 weeks' duration. We included studies reported as full text, those published as abstract only and unpublished data. We did not exclude studies on the basis of language or blinding.

\section{Types of participants}

We included adults (aged $\geq 18$ years) whose asthma was well controlled for a minimum of three months on at least a moderate dose of ICS (i.e. a dose of at least $400 \mathrm{mcg}$ beclomethasone dipropionate (BDP) or equivalent) (SIGN/BTS 2016). We classified asthma control according to predefined criteria, for example, as per the criteria described in GINA 2016 (i.e. daily symptoms twice or less often per week, use of rescue inhaler twice or less often per week, no nocturnal symptoms and no limitation to daily activities), or as per the asthma control questionnaire (i.e. a score less than 1.5). We excluded participants who had the following comorbidities/ 
characteristics: chronic obstructive pulmonary disease (COPD), bronchiectasis or any other respiratory comorbidity.

If studies enrolled adults and adolescents (aged 10 to 17 years) (WHO 2014), and data were not reported separately, we included the study if the mean age of participants in the intervention and comparator groups was 18 years or older.

\section{Types of interventions}

We included trials that compared the following.

1. Reduction in the dose of ICS versus no change in the dose of ICS, in people with asthma whose condition was well controlled on at least a moderate dose of any ICS, but who were not taking a concomitant LABA.

2. Reduction in the dose of ICS versus no change in the dose of ICS, in people with asthma whose condition was well controlled on at least a moderate dose of any ICS and who were taking a concomitant LABA.

For both comparisons, a different ICS could be used in the intervention and comparator groups, provided both groups used the same beclomethasone dipropionate (BDP) equivalent dose of ICS ( $\geq 400 \mathrm{mcg}$ ) before randomisation. We excluded studies in which treatment with ICS was stopped, as this relates to a different clinical question. We included studies that permitted use of shortacting reliever medications, provided they were not part of the randomised treatment.

For the latter comparison (patients taking a concomitant LABA), several studies included participants who used combination (ICS/LABA) inhalers; we excluded studies in which randomised treatment included a concurrent dose reduction of both ICS and LABA, because this strategy relates to a different clinical question. We also excluded studies if randomised treatment involved a stepdown to single inhaler therapy (i.e. 'single inhaler maintenance and reliever therapy' (SMART)) with a lower dose of ICS, because this also relates to a different clinical question that is addressed in another review (Kew 2013).

\section{Types of outcome measures}

\section{Primary outcomes}

1. Exacerbations requiring oral corticosteroids

2. Asthma control (measured on a validated scale; preferred measure is the Asthma Control Questionnaire (ACQ) score)

3. All-cause serious adverse events

4. Steroid-related adverse events

\section{Secondary outcomes}

1. Health-related quality of life (measured on a validated scale; preferred measure is the Asthma Quality of Life Questionnaire (AQLQ) score)

2. Lung function indices (preferred measure is trough $\mathrm{FEV}_{1}$ )

3. Exacerbations requiring hospitalisation

4. Exacerbations requiring an emergency department visit

5. Mortality

Reporting one or more of these outcomes in a trial was not an inclusion criterion.

\section{Search methods for identification of studies}

\section{Electronic searches}

We identified trials from the Cochrane Airways Group Specialised Register (CAGR), which is maintained by the Group's Trials Search Co-ordinator. The Register contains trial reports identified through systematic searches of bibliographic databases including the Cochrane Central Register of Controlled Trials (CENTRAL), MEDLINE, Embase, the Cumulative Index to Nursing and Allied Health Literature (CINAHL), the Allied and Complementary Medicine Database (AMED) and PsycINFO, and via handsearches of respiratory journals and meeting abstracts (Appendix 1). We searched all records in the Cochrane Airways Group Specialised Register using the search strategy presented in Appendix 2.

We also conducted a search of ClinicalTrials.gov (https:// clinicaltrials.gov/) and the World Health Organization (WHO) International Clinical Trials Registry Platform (ICTRP) Search Portal (http://apps.who.int/trialsearch/). We searched all databases from their inception to July 2016, and we imposed no restriction on language of publication.

\section{Searching other resources}

We checked the reference lists of all primary studies and review articles for additional references. We searched relevant manufacturers' websites for trial information.

On 4 October 2016, we searched for errata and retractions from included studies published in full text on PubMed.

\section{Data collection and analysis}

\section{Selection of studies}

Two review authors (DE, NH) independently screened titles and abstracts for inclusion of all potential studies identified as a result of the search and coded them as 'retrieve' (eligible or potentially eligible/unclear) or 'do not retrieve'. Two review authors (DE, NH or IC) independently retrieved and screened the full-text reports/ publications to identify studies for inclusion, and to identify and record reasons for exclusion of ineligible studies. We resolved disagreements through discussion, or, if required, we consulted a third review author (PM). We identified and excluded duplicates and collated multiple reports of the same study, so that each study rather than each report was the unit of interest in the review. We recorded the selection process in sufficient detail to complete a Preferred Reporting Items for Systematic Reviews and MetaAnalyses (PRISMA) flow diagram and the Characteristics of excluded studies table.

\section{Data extraction and management}

We used a data collection form to collect information on study characteristics and outcome data after piloting the form on at least one study included in the review. Two review authors (DE, NH) extracted the following study characteristics from included studies in duplicate.

1. Methods: study design, total duration of study, details of any 'run-in' period, number of study centres and locations, study setting, withdrawals, dates of study.

2. Participants: $N$, mean age, age range, gender, severity of condition, diagnostic criteria, baseline lung function, smoking 
history, inclusion criteria and exclusion criteria and details of criteria for stepping down treatment (clinical, e.g. symptoms, lung function, exacerbation history; airway responsiveness, e.g. mannitol challenge; inflammatory biomarkers, e.g. exhaled nitric oxide).

3. Interventions: intervention, comparison, concomitant medications, excluded medications.

4. Outcomes: primary and secondary outcomes specified and collected, time points reported.

5. Notes: funding for trial, notable conflicts of interest of trial authors.

Two review authors (IC, DE) independently extracted outcome data from included studies. We noted in the Characteristics of included studies table if outcome data were not reported in a useable way. We resolved disagreements by reaching consensus or by involving a third review author (PM). One review author (DE) transferred data into Cochrane's statistical software, Review Manager 2014. We double-checked that data were entered correctly by comparing data presented in the systematic review against study reports. A second review author $(\mathrm{NH})$ spot-checked study characteristics for accuracy against the trial report.

\section{Assessment of risk of bias in included studies}

Two review authors (DE, PM) independently assessed risk of bias for each study using Cochrane's tool for assessing risk of bias (Higgins 2011). We resolved disagreements by discussion or by consultation with another review author (IC or $\mathrm{NH}$ ).

We assessed risk of bias according to the following domains.

1. Random sequence generation.

2. Allocation concealment.

3. Blinding of participants and personnel.

4. Blinding of outcome assessment.

5. Incomplete outcome data.

6. Selective outcome reporting.

7. Other bias.

We graded each potential source of bias as high, low or unclear and provided a quote from the study report together with a justification for our judgement in a 'Risk of bias table'. We summarised risk of bias judgements across different studies for each of the domains listed. We considered blinding separately for different key outcomes when necessary (e.g. for unblinded outcome assessment, risk of bias for all-cause mortality may be very different from that observed for a patient-reported pain scale). When information on risk of bias was related to unpublished data or correspondence with a trialist, we noted this in the 'Risk of bias table'.

When considering treatment effects, we took into account the risk of bias for studies that contributed to that outcome.

\section{Assesment of bias in conducting the systematic review}

We conducted the review according to this published protocol and reported any deviations from it in the Differences between protocol and review section of the systematic review.

\section{Measures of treatment effect}

We analysed dichotomous data as odds ratios (ORs), and continuous data as mean differences (MDs). We entered data presented as a scale with a consistent direction of effect. When included studies reported dichotomous data as risk ratios (RRs) or hazard ratios (HRs), we calculated and presented the ORs.

We undertook meta-analyses only when this was meaningful (i.e. when treatments, participants and the underlying clinical question were similar enough for pooling to make sense).

We narratively described skewed data reported as medians and interquartile ranges.

When multiple trial arms were reported in a single trial, we included only the relevant arms. If two comparisons (e.g. drug A vs placebo and drug B vs placebo) were combined in the same meta-analysis, we halved the control group to avoid double-counting.

When the duration of studies included in an analysis varied by more than three months, we performed sensitivity analyses to examine whether study duration influenced the treatment effect. If an influence of study duration was apparent, we re-expressed ORs as a variety of numbers needed to treat (NNTs) across a range of assumed control risks (control group risks are likely to vary in studies of different duration) (Higgins 2011).

\section{Unit of analysis issues}

For dichotomous outcomes, we used participants, rather than events, as the unit of analysis (i.e. the number of participants admitted to hospital at least once rather than the number of admissions per participant). We planned to also analyse exacerbations leading to admission or to a course of oral steroids as rate ratios and time to event data, if these data were presented.

\section{Dealing with missing data}

We contacted investigators or study sponsors to verify key study characteristics and to obtain missing numerical outcome data when possible (e.g. when a study was identified as "abstract only"). When this was not possible, and missing data were thought to introduce serious bias, we explored the impact of including such studies in the overall assessment of results by performing a sensitivity analysis.

\section{Assessment of heterogeneity}

We used the 12 statistic to measure heterogeneity among the trials in each analysis. If we identified substantial heterogeneity (i.e. $1^{2} \geq$ $50 \%$ ), we reported this and explored possible causes by performing prespecified subgroup analysis.

\section{Assessment of reporting biases}

As we included only six studies, we were not able to pool more than 10 trials to create a funnel plot to explore possible small study and publication biases.

\section{Data synthesis}

We used a random-effects model and planned to perform a sensitivity analysis using a fixed-effect model. 


\section{'Summary of findings' table}

We created a 'Summary of findings' table using all of the outcomes listed above (Types of outcome measures), with the exception of mortality and exacerbations requiring an emergency department visit. We used the five Grading of Recommendations Assessment, Development and Evaluation (GRADE) considerations (study limitations, consistency of effect, imprecision, indirectness and publication bias) to assess the quality of a body of evidence as it relates to studies that contributed data to the meta-analyses for prespecified outcomes. We used methods and recommendations described in the Cochrane Handbook for Systematic Reviews of Interventions and GRADEpro (GRADEproGDT) software (http:// www.guidelinedevelopment.org/). We justified all decisions to downgrade or upgrade the quality of studies by using footnotes, and we made comments to aid readers' understanding of the review when necessary.

\section{Subgroup analysis and investigation of heterogeneity}

We planned to carry out the following subgroup analyses.

1. Rate of dose reduction (e.g. $25 \%$ dose reduction vs $50 \%$ dose reduction).

2. Separate inhaler therapy versus combination inhaler therapy (i.e. ICS/LABA).

We planned to use the following primary outcomes in subgroup analyses.

1. Exacerbations requiring oral corticosteroids.

2. Asthma control.

We used the formal test for subgroup interactions provided in Review Manager 2014.

\section{Sensitivity analysis}

We planned to carry out the following sensitivity analyses.
1. Unpublished data (i.e. no peer-reviewed full-text publication available).

2. Studies at unclear or high risk of bias for blinding.

3. Fixed-effect versus random-effects models.

4. Duration of included studies (e.g. short term (less than three months) vs longer term (more than three months)).

5. Studies at high risk of any other bias versus those at low risk of any other bias.

\section{RE S U L T S}

\section{Description of studies}

The Characteristics of included studies table presents details of the included studies. We reported in the Characteristics of excluded studies table reasons for exclusion of studies considered during review of full-text articles.

\section{Results of the search}

We identified 983 records by performing electronic searches of bibliographic databases and an additional 53 records by searching clinicaltrials.gov. Of a total of 1034 records (two duplicates removed), we excluded most $(n=972)$ upon screening titles and abstracts. We examined full-text articles of the remaining 62 records and excluded 53 records (reporting 41 studies), primarily because the intervention did not meet the criteria for inclusion in this review ( $n=27$ studies). The interventions considered were typically complex and difficult to separate from other components; this resulted in a high rate of exclusions at full-text review stage. Other reasons for exclusion at this stage included 'wrong study design' ( $\mathrm{n}$ $=8)$, 'wrong comparator' $(n=3)$, 'wrong route of administration' ( $n$ $=2$ ) and 'wrong patient population' ( $n=1)$. The remaining 11 records reported the findings of six studies, which we included in this review. Figure 1 depicts the flow of information through the different stages of this systematic review. 
Figure 1. Study flow diagram.

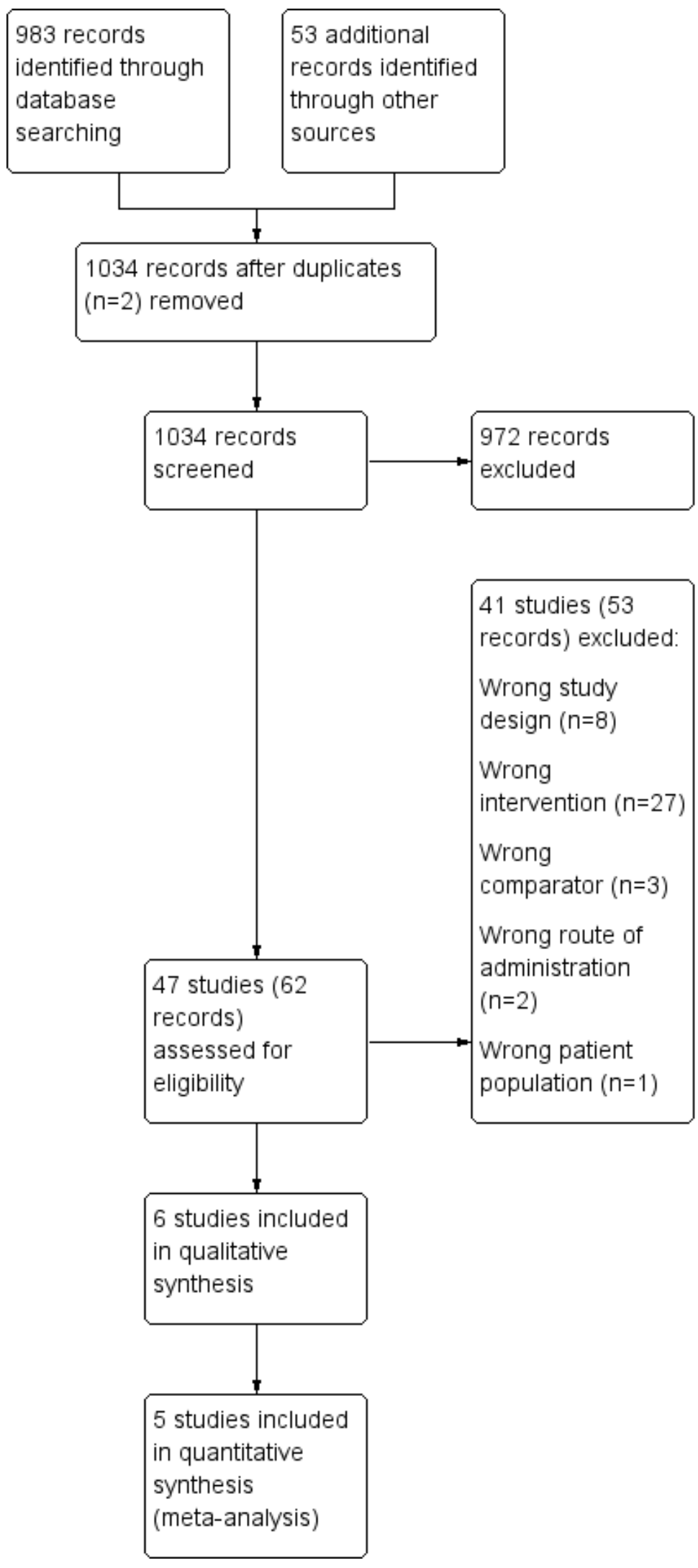




\section{Included studies}

Six studies met the inclusion criteria and contributed data to the analyses (Godard 2008; Gunn 1997; Hawkins 2003; Juniper 1991; Knox 2007; Magnussen 2000). The six included studies randomised a total of 1654 participants (ICS dose reduction, no concomitant LABA: $n=892$; ICS dose reduction, concomitant LABA: $n=762$ ). The largest (Gunn 1997) and smallest (Juniper 1991) studies included 631 and 28 participants, respectively. All included studies were reported as full peer-reviewed articles.

\section{Methods}

All included studies were RCTs with a parallel design that compared a fixed dose of ICS versus a reduced dose of ICS. Two studies included three arms (Godard 2008; Gunn 1997), and in one of these, only two out of three arms were relevant to this review (Godard 2008). Five studies were performed as double-blind, and one study was open-label (Gunn 1997). Five studies reported a run-in period (duration two to eight weeks), and one study was an extension of a previous 12-month study (Juniper 1991). Duration of the treatment period ranged from 12 to 52 weeks (mean duration 21 weeks; median duration 14 weeks). Outcome data were reported at the last time point reported for each study. Most studies were performed in Europe (Godard 2008; Gunn 1997; Hawkins 2003; Knox 2007; Magnussen 2000), and one study in Canada (Juniper 1991). Two studies were conducted in the setting of primary care (Gunn 1997; Hawkins 2003), two were conducted in the secondary care setting (Juniper 1991; Magnussen 2000) and two reported no information on setting (Godard 2008; Knox 2007).

\section{Participants}

We included studies that recruited adult participants aged $\geq 18$ years or in which most participants were adults. When reported, the age range of participants across included studies was 16.2 to 86 years (Godard 2008; Gunn 1997; Hawkins 2003; Knox 2007); in the two studies for which the age range was not reported, the mean age of participants was approximately 40 years (Juniper 1991; Magnussen 2000). Participants in the included studies had asthma that was generally well controlled by regular preventive therapy (i.e. step 2 of the BTS/SIGN guidelines; SIGN/BTS 2016) (Gunn 1997; Juniper 1991; Knox 2007; Magnussen 2000), with the use of high-dose ICS ( $\geq 1000 \mu \mathrm{g}$ BDP) (Hawkins 2003) or with an addon therapy (i.e. step 3 of the BTS/SIGN guidelines) (Godard 2008). When reported, most participants were non-smokers (Godard 2008; Hawkins 2003; Knox 2007).

\section{Interventions}

All included studies compared a $50 \%$ to $60 \%$ reduction in dose of ICS versus no change in ICS dose. In terms of the type and baseline dose of ICS, studies included a variety of comparisons: fluticasone propionate (FP) $250 \mu \mathrm{g}$ twice daily versus ciclesonide $160 \mu \mathrm{g}$ once daily (representing a $50 \%$ reduction according to Global Initiative for Asthma (GINA) guidelines) (Knox 2007); a 50\% reduction in dose of any ICS (as used before the study) (Hawkins 2003); salmeterol/ fluticasone combination (SFC) 50/100 $\mu$ g twice daily versus no change (SFC 50/250 $\mu$ g twice daily) (Godard 2008); a 50\% reduction in dose of budesonide versus no change in budesonide dose (any dose) (Juniper 1991); and chlorofluorocarbon beclomethasone $1000 \mu \mathrm{g} /$ day versus hydrofluoroalkane beclomethasone $400 \mu \mathrm{g} /$ day (<50\% reduction) (Magnussen 2000). The study comparison reported by Gunn and colleagues (Gunn 1997) was as follows:
Participants on an initial high dose of ICS (budesonide $400 \mu \mathrm{g}$ twice daily or beclomethasone $400 \mu \mathrm{g}$ twice daily or beclomethasone $500 \mu \mathrm{g}$ twice daily delivered via a pressurised metered-dose inhaler (pMDI) and spacer device) were randomised to receive budesonide $200 \mu \mathrm{g}$ twice daily via a Turbohaler, or $400 \mu \mathrm{g}$ once daily (i.e. both groups represent a halving of the initial ICS dose). Participants on an initial low dose of ICS (budesonide or beclomethasone 200 $\mu \mathrm{g}$ twice daily) were randomised to receive budesonide $100 \mu \mathrm{g}$ twice daily via a Turbuhaler, or $200 \mu \mathrm{g}$ once daily (i.e. both groups represent a halving of the initial ICS dose). There was no change in initial dose of budesonide or beclomethasone in the control group (Gunn 1997).

Inhaler devices varied across studies but were consistent between intervention and control groups in at least three of the six included studies. One study used a Diskus dry powder inhaler (Godard 2008); another used the Autohaler, a breath-actuated metered-dose inhaler (MDI) (Magnussen 2000); one study used a hydrofluoroalkane MDI (Knox 2007); another did not report the device used (Juniper 1991); one study permitted the use of an MDI or a dry powder inhaler as long as the same device was used throughout the study (Hawkins 2003); and another used the Turbohaler for participants in the intervention group and an MDI for those in the comparator group (Gunn 1997) and considered the two inhaler types to be equivalent for a given dose.

\section{Outcomes}

Outcomes reported were inconsistent across included studies. All studies reported data on asthma control, although several studies used scales that were not validated and thus did not contribute data to the meta-analysis. Most studies reported exacerbations requiring oral corticosteroids (OCS) (Godard 2008; Hawkins 2003; Knox 2007; Magnussen 2000), all-cause serious adverse events (SAEs) (Godard 2008; Gunn 1997; Hawkins 2003; Knox 2007) and lung function (Godard 2008; Gunn 1997; Juniper 1991; Knox 2007; Magnussen 2000), although reported measures of lung function varied across studies. Two studies reported quality of life (QoL): One study used both the Juniper Asthma QoL Questionnaire and the Dupuy Psychological General Well Being Index (Gunn 1997), and the second study used the EuroQoL questionnaire and the St George's Respiratory Questionnaire (Hawkins 2003). Steroid related AEs and exacerbations requiring hospitalisation were each reported by two studies (Knox 2007 and Magnussen 2000; Godard 2008 and Hawkins 2003, respectively). Mortality and exacerbations requiring an emergency department visit were each reported by one study (Godard 2008 and Hawkins 2003, respectively).

\section{Excluded studies}

We excluded 53 references (related to 41 studies) following assessment of full-text articles (Characteristics of excluded studies). We excluded 27 studies as they used an intervention that was not relevant to this review (e.g. a dose reduction of ICS was not used, or a concomitant reduction in ICS and LABA was used). Eight studies were excluded because they used a study design not appropriate for this review (e.g. cross-over or non-randomised design). We excluded six studies because they used a comparator not relevant to this review $(n=3$; e.g. a dose reduction in the control group) or a route of administration not relevant to this review was used ( $n=2$; e.g. the intervention was OCS, not ICS) or because the patient population studied was not relevant $(n=1$; e.g. participants were children). 


\section{Risk of bias in included studies}

Please refer to the Characteristics of included studies tables for details on risk of bias and for supporting evidence for each study. Figure 2 provides a summary of risk of bias judgements, presented by study and domain (sequence generation, allocation concealment, blinding, incomplete data, selective reporting and 'other'). Figure 3 depicts the risk of bias for each domain, presented as percentages across all included studies.

Figure 2. Risk of bias summary: review authors' judgements about each risk of bias item for each included study.

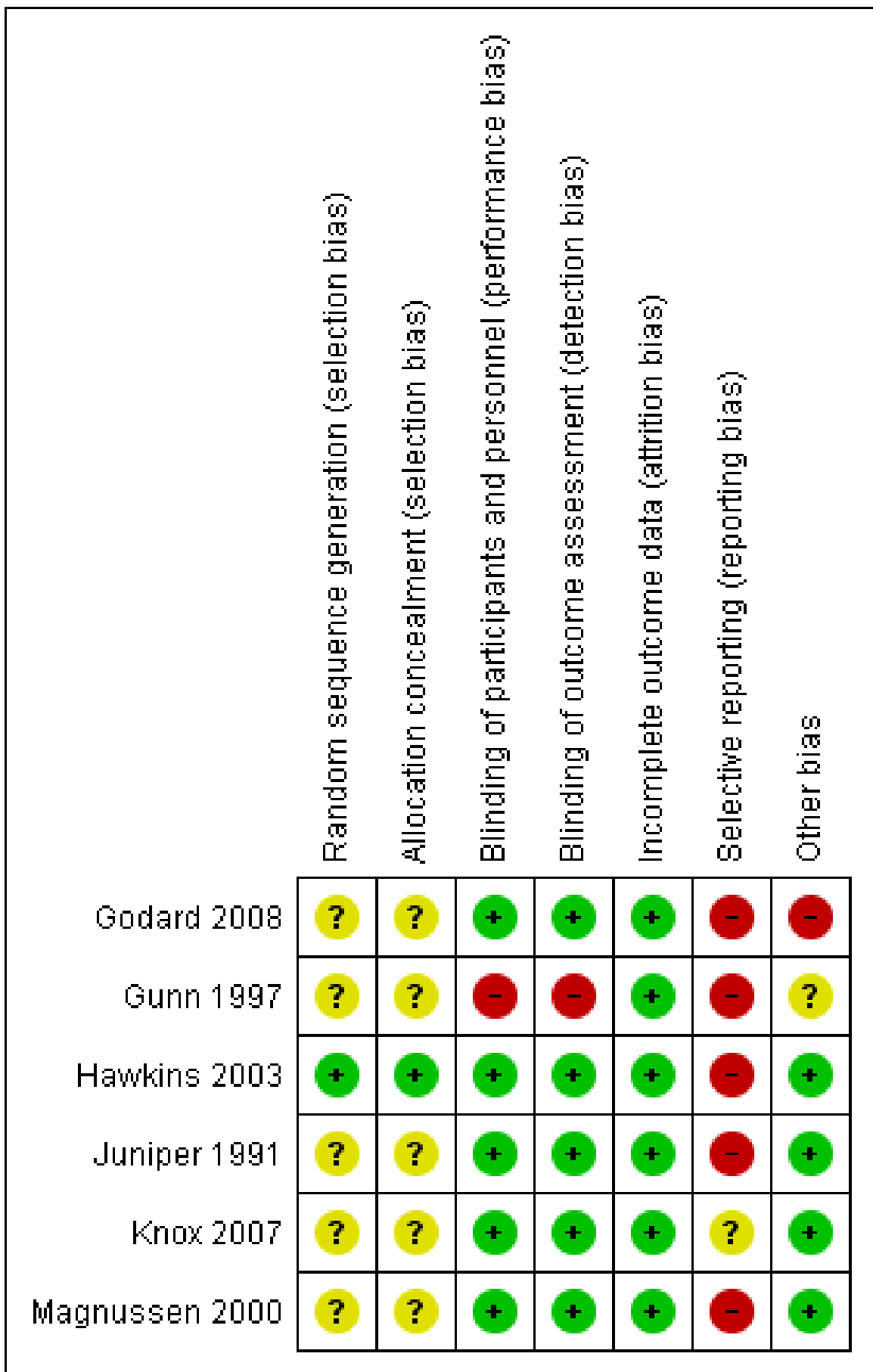


Figure 3. Risk of bias graph: review authors' judgements about each risk of bias item presented as percentages across all included studies.

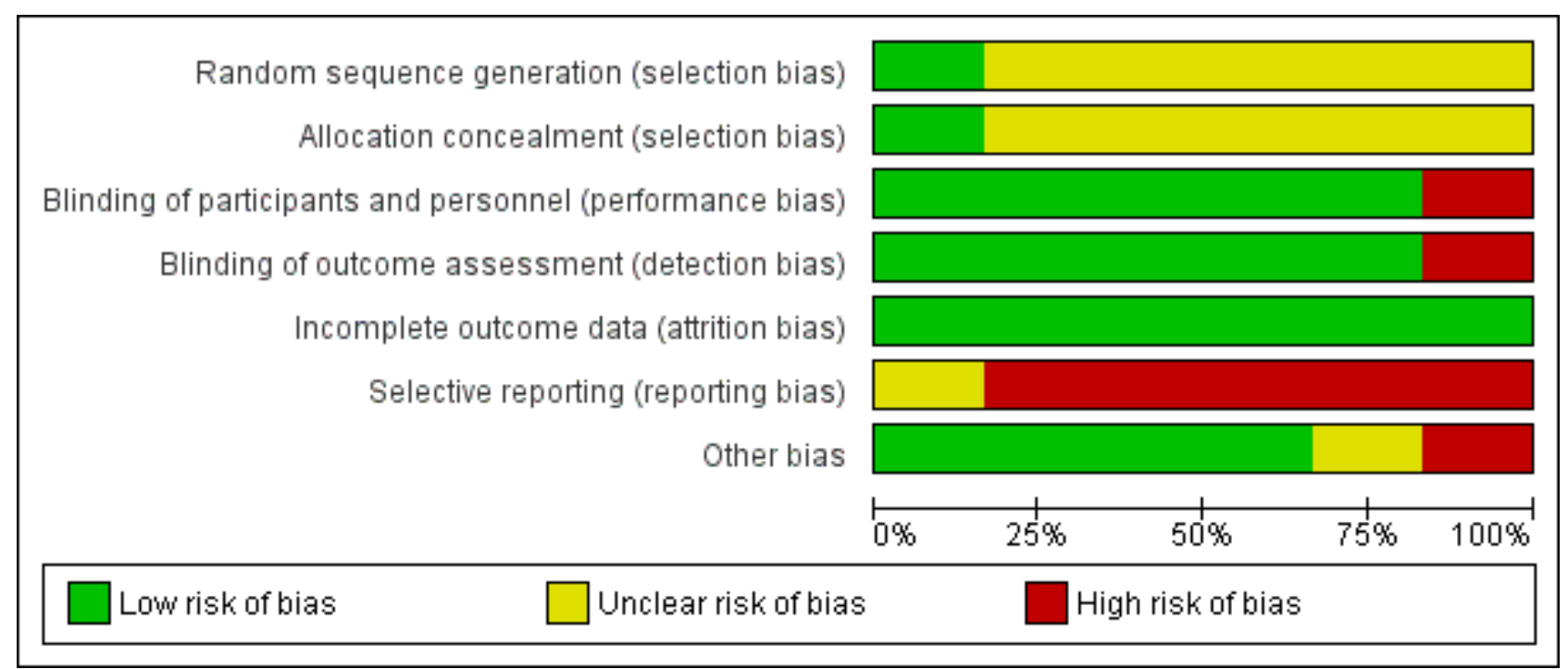

\section{Allocation}

Most studies (five of six) provided insufficient information regarding methods of random sequence generation and concealment of treatment allocation to allow a judgement on risk of bias (Godard 2008; Gunn 1997; Juniper 1991; Knox 2007; Magnussen 2000); therefore, the risk of bias for these studies was unclear. One study (Hawkins 2003) used a computer-generated randomisation sequence and concealed allocation method, and was considered to be at low risk for selection bias.

\section{Blinding}

We considered five of six studies (Godard 2008; Hawkins 2003; Juniper 1991; Knox 2007; Magnussen 2000) to have low risk of performance and detection bias, as participants, personnel and outcome assessors were blinded to treatment allocation through adequate methods. One study (Gunn 1997) used an open-label design, in which participants, personnel and outcome assessors were not blinded to treatment allocation; we considered this study to be at high risk of both performance and detection bias.

\section{Incomplete outcome data}

We considered all studies to be at low risk of attrition bias on the basis of low and balanced rates of participant withdrawal, which were adequately documented in the trial report.

\section{Selective reporting}

We judged five studies (Godard 2008; Gunn 1997; Hawkins 2003; Juniper 1991; Magnussen 2000) to be at high risk of reporting bias because no study protocol was available and there appeared to be either non-standard presentation of the data or selective reporting of data that were likely recorded. One study (Knox 2007) appeared to report a fairly comprehensive set of outcomes (i.e. exacerbations, steroid-related AEs, all-cause SAEs, lung function and asthma control); however, a protocol was not available, so we judged the risk of bias as unclear.

\section{Other potential sources of bias}

We judged four studies to be at low risk of other bias, as no other concerns were identified (Hawkins 2003; Juniper 1991; Knox 2007; Magnussen 2000). We considered Godard 2008 to be at high risk of other bias because, contrary to the methods described, investigators randomised a relatively high proportion of participants who had asthma that was not well controlled and included them in the full analysis set. We judged Gunn 1997 to be at unclear risk of bias because there appeared to be some changes in the inhaler used to deliver the ICS at the same time as changes in dose, although we noted that the two inhaler types were considered equivalent for a given dose.

\section{Effects of interventions}

See: Summary of findings for the main comparison ICS dose reduction compared with no change in ICS dose (no concomitant LABA) for adults with asthma; Summary of findings 2 ICS dose reduction compared with no change in ICS dose (concomitant LABA) for adults with asthma

\section{Structure of the analysis}

As per the protocol, we chose to analyse participants who were receiving a concomitant $L A B A$ separately from those who were not receiving a concomitant $\angle A B A$.

\section{Structure of the meta-analysis}

We created two main comparison headings within the analysis tree. For each comparison, we elected to perform a meta-analysis only when interventions and outcomes were sufficiently similar for pooling of the data.

\section{Participants not taking concomitant a LABA: ICS reduction versus no change in ICS dose}

This comparison comprised all studies that compared a reduction in the dose of ICS versus no change in ICS dose among participantsnot taking a concomitant LABA (Gunn 1997; Knox 2007; Magnussen 2000). 
Participants taking a concomitant LABA: ICS reduction versus no change in ICS dose

This comparison comprised all studies that compared a reduction in the dose of ICS versus no change in ICS dose among participants taking a concomitant LABA (Godard 2008; Hawkins 2003; Juniper 1991)

\section{Structure of the narrative synthesis}

In the following sections, we present a narrative summary of study results according to the prespecified outcomes. We present primary outcomes (exacerbations requiring OCS, asthma control, all-cause SAEs, steroid-related AEs) followed by secondary outcomes (health-related QoL, lung function, exacerbations requiring hospitalisation, exacerbations requiring an emergency department visit, mortality). For each outcome, we describe the effect of the intervention among participants not taking a concomitant $L A B A$ followed by the effect of the intervention among participants taking a LABA.

\section{Primary outcomes}

\section{Exacerbations requiring oral corticosteroids}

ICS stepdown, no concomitant LABA

Stepping down the dose of ICS resulted in no clear benefit or harm with respect to exacerbations requiring treatment with oral steroids (odds ratio (OR) 1.86, 95\% confidence interval $(\mathrm{Cl}) 0.16$ to 21.09 ; $\mathrm{n}$ $=261$ participants, two studies; $\left.\right|^{2}=0 \%$; Analysis 1.1; Figure 4). For people who stepped down their dose of ICS, we estimated that six more people per 1000 would have an exacerbation requiring oral steroids, but the confidence intervals ranged from seven fewer to 132 more people per 1000 . We rated the quality of the evidence as very low after downgrading twice for imprecision (no events were reported by one of the contributing studies, and confidence intervals include the null effect (risk ratio (RR) 1.0) and appreciable benefit (RR 0.75) or harm (RR 1.25)) and once for indirectness, as the evidence was based on studies operating out of specialist centres.

Figure 4. Forest plot of comparison: 1 ICS dose reduction versus no change in ICS dose (no concomitant LABA), outcome: 1.1 Exacerbation requiring OCS.

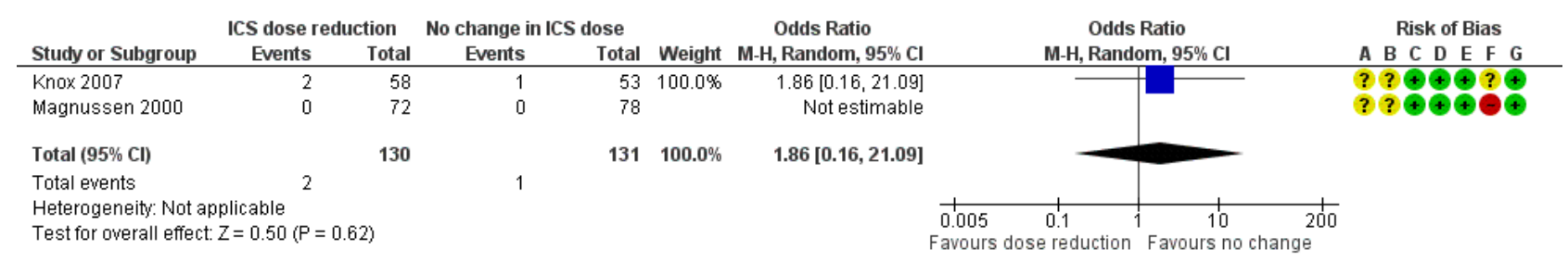

Risk of bias legend

(A) Random sequence generation (selection bias)

(B) Allocation concealment (selection bias)

(C) Blinding of participants and personnel (performance bias)

(D) Blinding of outcome assessment (detection bias)

(E) Incomplete outcome data (attrition bias)

(F) Selective reporting (reporting bias)

(G) Other bias

\section{ICS stepdown, concomitant LABA}

Stepping down the dose of ICS resulted in no clear benefit or harm with respect to exacerbations requiring treatment with oral steroids (OR $1.31,95 \% \mathrm{Cl} 0.82$ to $2.08 ; \mathrm{n}=569$ participants; two studies; $\mathrm{I}^{2}$ $=0 \%$; Analysis 2.1; Figure 5). For people who stepped down their dose of ICS (versus those with no change in ICS dose), we estimated that 38 more people per 1000 would have an exacerbation requiring oral steroids, but the confidence intervals ranged from 23 fewer to 118 more people per 1000 . We rated the quality of the evidence as low after downgrading once for risk of bias (selective reporting) and once for imprecision (confidence intervals include null effect and appreciable benefit (RR 0.75) or harm (RR 1.25)).

Figure 5. Forest plot of comparison: 2 ICS dose reduction versus no change in ICS dose (concomitant LABA), outcome: 2.1 Exacerbation requiring OCS.

\begin{tabular}{|c|c|c|c|c|c|c|c|c|c|}
\hline \multirow[b]{2}{*}{ Study or Subgroup } & \multicolumn{2}{|c|}{ ICS dose reduction } & \multicolumn{2}{|c|}{ No change in ICS dose } & \multicolumn{2}{|r|}{ Odds Ratio } & \multirow{2}{*}{\multicolumn{2}{|c|}{$\begin{array}{c}\text { Odds Ratio } \\
\text { M-H, Random, } 95 \% \mathrm{Cl} \\
\end{array}$}} & Risk of Bias \\
\hline & Events & Total & Events & Total & Weight & M-H, Random, $95 \% \mathrm{Cl}$ & & & A B C D E F G \\
\hline Godard 2008 & 12 & 156 & 9 & 154 & $26.9 \%$ & $1.34[0.55,3.28]$ & & & \\
\hline Hawkins 2003 & 40 & 130 & 33 & 129 & $73.1 \%$ & $1.29[0.75,2.23]$ & & & 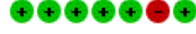 \\
\hline Total $(95 \% \mathrm{Cl})$ & & 286 & & 283 & $100.0 \%$ & $1.31[0.82,2.08]$ & & & \\
\hline Total events & 52 & & 42 & & & & & & \\
\hline $\begin{array}{l}\text { Heterogeneity: } \operatorname{Tau}^{2} \\
\text { Test for overall effect }\end{array}$ & $\begin{array}{l}0.00 ; \mathrm{Ch}^{2}= \\
\mathrm{Z}=1.13(\mathrm{P}=\end{array}$ & $\begin{array}{l}0, d f=1 \\
6)\end{array}$ & $(P=0.94) ;\left.\right|^{2}=0 \%$ & & & & $\begin{array}{cc}0.2 & 0.5 \\
\text { Favours dose reduction }\end{array}$ & 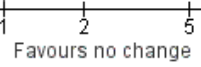 & \\
\hline $\begin{array}{l}\text { Risk of bias leqend } \\
\text { (A) Random sequen } \\
\text { (B) Allocation concea } \\
\text { (C) Blinding of partici } \\
\text { (D) Blinding of outcor } \\
\text { (E) Incomplete outco } \\
\text { (F) Selective reportin } \\
\text { (G) Other bias }\end{array}$ & $\begin{array}{l}\text { e generation } \\
\text { ment (select } \\
\text { ants and pe } \\
\text { e assessm } \\
\text { he data (attri } \\
\text { (reporting b }\end{array}$ & $\begin{array}{l}\text { lection } \\
\text { bias) } \\
\text { nnel (pe } \\
\text { (detecti } \\
\text { bias) }\end{array}$ & $\begin{array}{l}\text { bias) } \\
\text { onformance bias) } \\
\text { on bias) }\end{array}$ & & & & & & \\
\hline
\end{tabular}




\section{Asthma control}

\section{ICS stepdown, no concomitant LABA}

Stepping down the dose of ICS resulted in no clear benefit or harm with respect to asthma control (mean difference (MD) $-0.22,95 \% \mathrm{Cl}$ -1.05 to $0.61 ; n=150$ participants; one study; Analysis 1.2). We rated the quality of the evidence as low after downgrading once for risk of bias (selective reporting) and once for indirectness (single study representative of a single setting and drug regimen).

\section{ICS stepdown, concomitant LABA}

Stepping down the dose of ICS resulted in no clear benefit or harm with respect to asthma control as measured by the short asthma morbidity score (change from baseline: MD $0.16,95 \% \mathrm{Cl}-0.34$ to $0.66 ; n=242$ participants; one study; scale 0 (perfect control) to 8 (very poor control); Analysis 2.2). We rated the quality of the evidence as low after downgrading once for risk of bias (selective reporting) and once for indirectness (single study representative of a single setting and drug regimen). Nor did stepping down the dose of ICS result in clear benefit or harm with respect to asthma control as measured by the Asthma Severity Questionnaire (MD
$1.13,95 \% \mathrm{Cl}-0.24$ to 2.49 ; scale 0 (best control) to 6 (worst control); Analysis 2.3). We rated the quality of the evidence as very low after downgrading once for risk of bias (selective reporting), once for indirectness (single study representative of a single setting and drug regimen) and once for imprecision (confidence intervals include the null effect (MD 0) and appreciable harm (MD 1.5)).

\section{All-cause SAES}

\section{ICS stepdown, no concomitant LABA}

Stepping down the dose of ICS resulted in no clear benefit or harm with respect to SAEs (OR $1.24,95 \% \mathrm{Cl} 0.25$ to $6.25 ; \mathrm{n}=742$ participants; two studies; $\left.\right|^{2}=5 \%$; Analysis 1.3; Figure 6). For people who stepped down their dose of ICS (versus those with no change in ICS dose), we estimated that 1 more person per 1000 would have an SAE, but confidence intervals ranged from six fewer to 37 more people per 1000. We rated the quality of the evidence as low after downgrading once for risk of bias (selective reporting) and once for imprecision (confidence intervals include the null effect and appreciable benefit (RR 0.75) or harm (RR 1.25)).

\section{Figure 6. Forest plot of comparison: 1 ICS dose reduction versus no change in ICS dose (no concomitant LABA),} outcome: 1.3 All-cause SAEs.

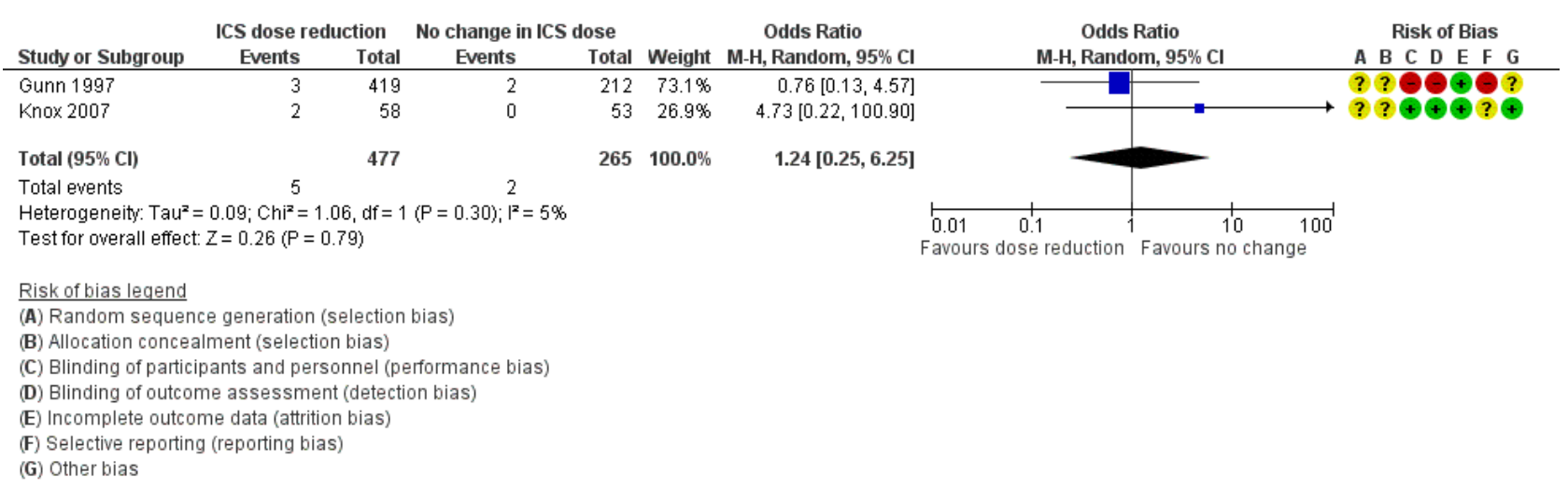

\section{ICS stepdown, concomitant LABA}

Stepping down the dose of ICS resulted in no clear benefit or harm with respect to SAEs (OR $0.60,95 \% \mathrm{Cl} 0.11$ to $3.33 ; \mathrm{n}=569$ participants; two studies; $1^{2}=35 \%$; Analysis 2.4; Figure 7). For people who stepped down their dose of ICS (versus those with no change in ICS dose), we estimated that 13 fewer people per 1000 would have an SAE, but the confidence intervals ranged from 31 fewer to 74 more people per 1000 . We rated the quality of the evidence as low after downgrading once for risk of bias (selective reporting) and once for imprecision (confidence intervals include null effect and appreciable benefit (RR 0.75) or harm (RR 1.25)). 
Figure 7. Forest plot of comparison: 2 ICS dose reduction versus no change in ICS dose (concomitant LABA), outcome: 2.4 All-cause SAEs.

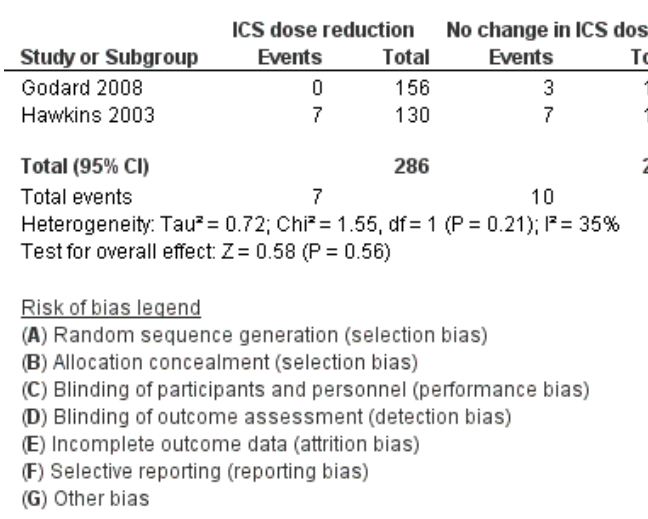

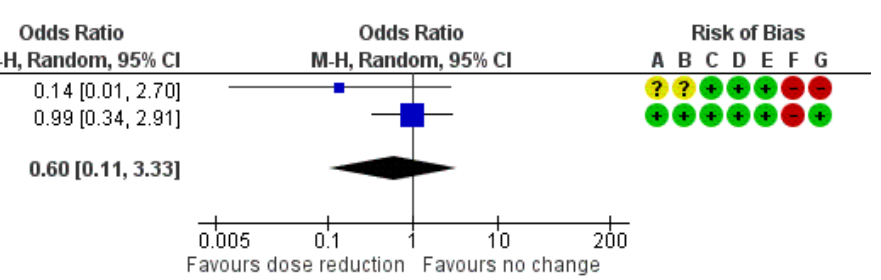

\section{Steroid-related AEs}

\section{ICS stepdown, no concomitant LABA}

Stepping down the dose of ICS resulted in no clear benefit or harm with respect to steroid-related AEs (OR $0.76,95 \% \mathrm{Cl} 0.16$ to 3.54 ; $\mathrm{n}$ $=261$ participants; two studies; $1^{2}=0 \%$; Analysis 1.4; Figure 8). For people who stepped down their dose of ICS (versus those with no change in ICS dose), we estimated that eight fewer people per 1000

would have a steroid-related $\mathrm{AE}$, but confidence intervals ranged from 26 fewer to 69 more people per 1000 . We rated the quality of the evidence as very low after downgrading once for risk of bias (selective reporting), once for indirectness (representative of specialist centres) and once for imprecision (confidence intervals include the null effect and appreciable benefit (RR 0.75) or harm (RR 1.25)).

Figure 8. Forest plot of comparison: 1 ICS dose reduction versus no change in ICS dose (no concomitant LABA), outcome: 1.4 Steroid-related AEs.

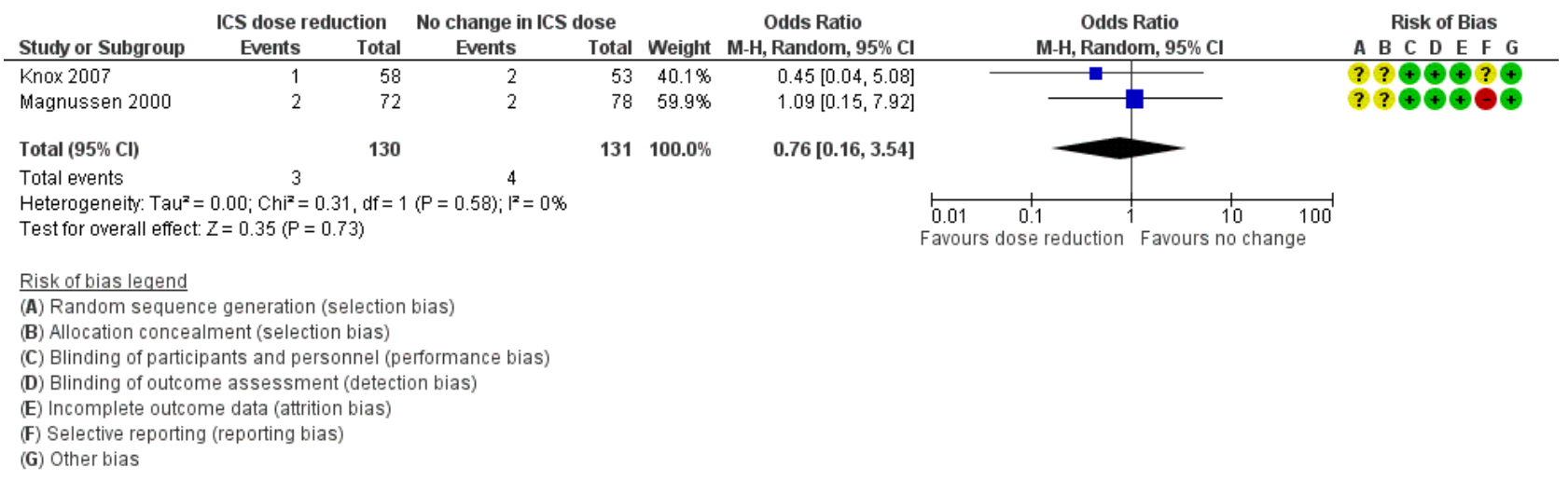

\section{ICS stepdown, concomitant LABA}

No included studies reported data for steroid-related AEs.

\section{Secondary outcomes}

\section{Health-related quality of life}

\section{ICS stepdown, no concomitant LABA}

There was a statistically significant difference in health-related quality of life (change from baseline) between groups as measured by the Asthma Quality of Life Questionnaire (change from baseline: MD $-0.21,95 \% \mathrm{Cl}-0.33$ to $-0.09 ; n=554$ participants, one study; scale 0 (worst) to 7 (best); Analysis 1.5). However, the mean difference and $95 \%$ confidence limits were below the minimal clinically important difference (MCID) of 0.5 , indicating no clinically relevant difference between groups. We rated the quality of the evidence as very low after downgrading twice for risk of bias (selective reporting and lack of blinding for a subjective outcome measure) and once for indirectness (single study representative of a single setting and drug regimen).

\section{ICS stepdown, concomitant LABA}

Stepping down the dose of ICS resulted in no benefit or harm with respect to health-related quality of life as measured by St George's Respiratory Scale (change from baseline: MD $0.13,95 \% \mathrm{Cl}-2.80$ to 3.06; $n=229$ participants, one study; scale 0 to 100 (greatest impact of chest disease on life); Analysis 2.6) or the EuroQoL (change from baseline: MD 2.32, 95\% Cl -1.64 to $6.28 ; n=219$ participants, one study; scale 0 to 100 (best imaginable health state); Analysis 2.5). With regards to the St George's Respiratory Scale, the mean difference and 95\% confidence limits were below the MCID of 4 units, indicating no clinically relevant difference between groups. We rated the quality of the evidence as low after downgrading once 
for risk of bias (selective reporting) and once for indirectness (single study representative of a single setting and drug regimen).

\section{Lung function}

ICS stepdown, no concomitant LABA

Stepping down the dose of ICS resulted in no benefit or harm with respect to lung function. There was no statistically significant change in percent predicted $\mathrm{FEV}_{1}(\mathrm{MD}-0.02,95 \% \mathrm{Cl}-0.12$ to $0.08 ; \mathrm{n}$ $=261$ participants, two studies; $\mathrm{I}^{2}=0 \%$; Analysis 1.7; Figure 9) nor in morning PEFR (MD $-5.98 \mathrm{~L} / \mathrm{min}, 95 \% \mathrm{Cl}-19.47$ to $7.51 ; \mathrm{n}=875$ participants, three studies; $\left.\right|^{2}=0 \%$; Analysis 1.6; Figure 10 ). We rated the quality of the evidence as low after downgrading once for risk of bias (selective reporting) and once for imprecision (confidence intervals include the null effect and appreciable benefit (RR 0.75) or harm (RR 1.25)).

Figure 9. Forest plot of comparison: 1 ICS dose reduction versus no change in ICS dose (no concomitant LABA), outcome: 1.7 Lung function, FEV $_{1}$ (L).

\begin{tabular}{|c|c|c|c|c|c|c|c|c|c|c|}
\hline \multirow[b]{2}{*}{ Study or Subgroup } & \multicolumn{3}{|c|}{ ICS dose reduction } & \multicolumn{3}{|c|}{ No change in ICS dose } & \multirow[b]{2}{*}{ Weight } & \multirow{2}{*}{$\begin{array}{l}\text { Mean Difference } \\
\text { IV, Random, } 95 \% \mathrm{Cl}\end{array}$} & \multirow{2}{*}{$\begin{array}{l}\text { Mean Difference } \\
\text { IV, Random, } 95 \% \mathrm{Cl}\end{array}$} & Risk of Bias \\
\hline & Mean & SD & Total & Mean & SD & Total & & & & A B C D E F G \\
\hline Knox 2007 & 3.132 & 0.2894 & 58 & 3.15 & 0.2839 & 53 & $85.9 \%$ & $-0.02[-0.12,0.09]$ & & ? ?૯૯૯ ? \\
\hline Magnussen 2000 & 2.75 & 0.7637 & 72 & 2.8 & 0.8832 & 78 & $14.1 \%$ & $-0.05[-0.31,0.21]$ & & ? ?૯૯ \\
\hline Total $(95 \% \mathrm{Cl})$ & & & 130 & & & 131 & $100.0 \%$ & $-0.02[-0.12,0.08]$ & & \\
\hline \multicolumn{11}{|c|}{ 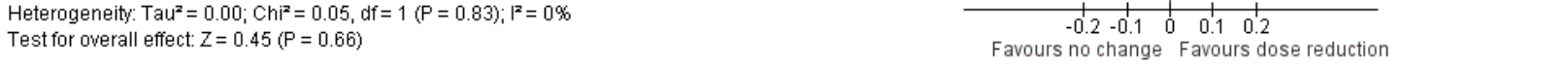 } \\
\hline
\end{tabular}

Risk of bias legend

(A) Random sequence generation (selection bias)

(B) Allocation concealment (selection bias)

(C) Blinding of participants and personnel (performance bias)

(D) Blinding of outcome assessment (detection bias)

(E) Incomplete outcome data (attrition bias)

(F) Selective reporting (reporting bias)

(G) Other bias

Figure 10. Forest plot of comparison: 1 ICS dose reduction versus no change in ICS dose (no concomitant LABA), outcome: 1.6 Lung function, PEFR morning (L/min).

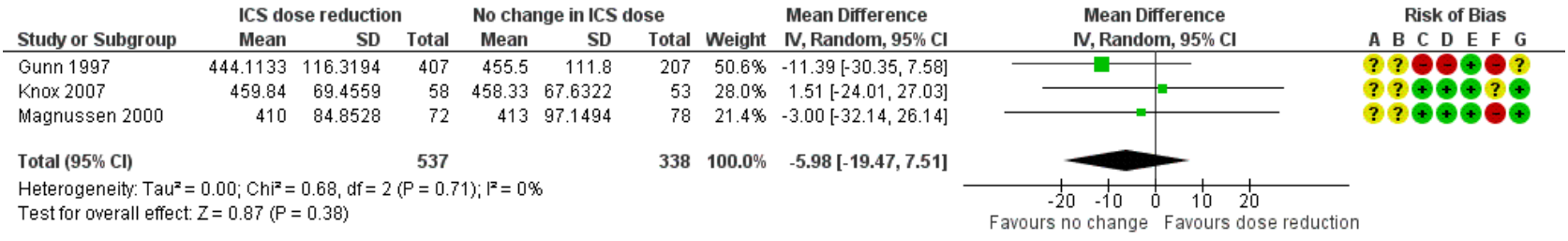

Risk of bias legend

(A) Random sequence generation (selection bias)

(B) Allocation concealment (selection bias)

(C) Blinding of participants and personnel (performance bias)

(D) Blinding of outcome assessment (detection bias)

(E) Incomplete outcome data (attrition bias)

(F) Selective reporting (reporting bias)

(G) Other bias

\section{ICS stepdown, concomitant LABA}

Stepping down the dose of ICS resulted in no benefit or harm with respect to lung function. There was no statistically significant between-group differences for change in percent predicted $\mathrm{FEV}_{1}$ from baseline (MD $-2.45,95 \% \mathrm{Cl}-8.88$ to $3.98 ; n=14$ participants, one study; Analysis 2.8) nor for change from baseline in morning PEFR (MD -4.54, 95\% Cl -12.08 to $3.00 ; n=310$ participants, one study; Analysis 2.7). We rated the quality of the evidence as very low after downgrading once for risk of bias (selective reporting), once for indirectness (single study representative of a single setting and drug regimen) and once for imprecision (wide $\mathrm{Cl}$ ).

\section{Exacerbations requiring hospitalisation}

ICS stepdown, no concomitant LABA

No studies reported the number of participants requiring hospitalisation.

\section{ICS stepdown, concomitant LABA}

Stepping down the dose of ICS resulted in no clear benefit or harm with respect to exacerbations requiring hospitalisation (OR 4.06, $95 \% \mathrm{Cl} 0.45$ to $36.86 ; \mathrm{n}=569$ participants, two studies; $\mathrm{l}^{2}=0 \%$; Analysis 2.9; Figure 11). For people who stepped down their dose of ICS (versus those with no change in ICS dose), we estimated that 10 more people per 1000 would have an exacerbation requiring hospitalisation, but the confidence intervals ranged from 2 fewer to 112 more people per 1000 . We rated the quality of the evidence as low after downgrading once for risk of bias (selective reporting) and once for imprecision (wide $\mathrm{Cl}$ ). 
Figure 11. Forest plot of comparison: 2 ICS dose reduction versus no change in ICS dose (concomitant LABA), outcome: 2.9 Exacerbation requiring hospitalisation.

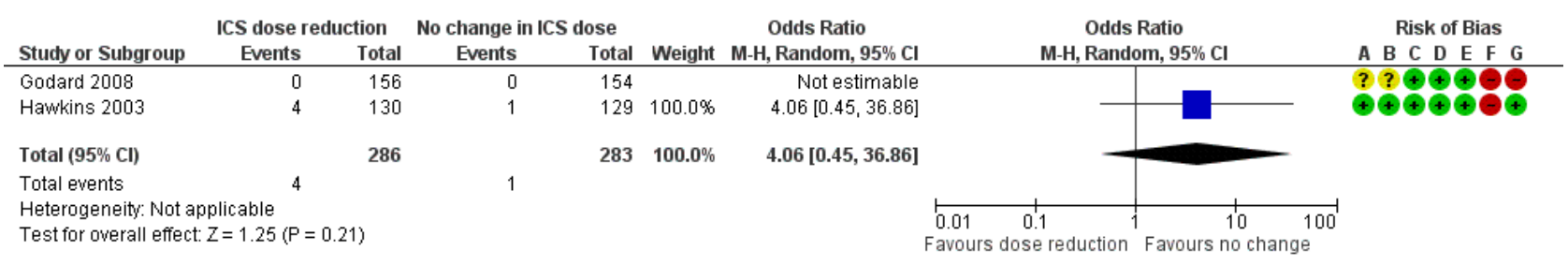

Risk of bias legend

(A) Random sequence generation (selection bias)

(B) Allocation concealment (selection bias)

(C) Blinding of participants and personnel (performance bias)

(D) Blinding of outcome assessment (detection bias)

(E) Incomplete outcome data (attrition bias)

(F) Selective reporting (reporting bias)

(G) Other bias

\section{Exacerbations requiring an emergency department visit}

\section{ICS stepdown, no concomitant LABA}

No studies reported the number of participants requiring an emergency department visit.

\section{ICS stepdown, concomitant LABA}

Stepping down the dose of ICS resulted in no clear benefit or harm with respect to exacerbations requiring an emergency department visit (OR 2.00, 95\% Cl 0.18 to 22.33 ; $n=259$ participants, one study; Analysis 2.10). For people who stepped down their dose of ICS (versus those with no change in ICS dose), we estimated that 7 more people per 1000 would have an exacerbation requiring an emergency department visit, but confidence intervals ranged from 7 fewer to 141 more people per 1000 . We rated the quality of the evidence as very low after downgrading once for risk of bias (selective reporting), once for imprecision (wide $\mathrm{Cl}$ ) and once for indirectness (single study representative of a single setting and drug regimen).

\section{Mortality}

ICS stepdown, no concomitant LABA

No studies reported mortality data.

\section{ICS stepdown, concomitant LABA}

Stepping down the dose of ICS resulted in no clear benefit or harm in terms of mortality; the single study reporting data $(\mathrm{N}=310$ participants; Analysis 2.11) reported no deaths in either group. We rated the quality of the evidence as very low after downgrading once for risk of bias (selective reporting), once for indirectness (single study representative of a single setting and drug regimen) and once for imprecision (no events reported).

\section{Subgroup analyses}

\section{Magnitude of dose reduction}

Review authors did not perform this prespecified subgroup analysis for either comparison because all of the included studies represented a $50 \%$ to $60 \%$ reduction in ICS dose.

\section{Separate ICS/LABA inhalers versus combination ICS/LABA inhaler}

This was relevant only to the second comparison (participants who were permitted to receive a concomitant LABA).

For exacerbations requiring oral corticosteroids, the use of individual ICS and LABA inhalers (Hawkins 2003) versus a combined inhaler (Godard 2008) did not appear to influence the overall OR (1.31, 95\% $\mathrm{Cl} 0.82$ to 2.08 ) because results of the two contributing studies were comparable (OR $1.29,95 \% \mathrm{Cl} 0.75$ to 2.23 (Hawkins 2003) and OR 1.34, 95\% Cl 0.55 to 3.28 (Godard 2008), respectively).

We could not perform a subgroup analysis for asthma control as only one study contributed data to each measure of asthma control (short asthma morbidity score (Hawkins 2003) and asthma severity questionnaire (Juniper 1991)).

\section{Sensitivity analyses}

It was not possible for review authors to conduct the planned sensitivity analyses because of the paucity of included studies contributing to each outcome examined.

\section{DISCUSSION}

\section{Summary of main results}

We included six studies, which randomised a total of 1654 participants (inhaled corticosteroid (ICS) dose reduction, no concomitant long-acting beta agonist (LABA): $n=892$ participants, three randomised controlled trials (RCTs); ICS dose reduction, concomitant LABA: $n=762$, three RCTs). All included studies were RCTs with a parallel design that compared a fixed dose of ICS with a $50 \%$ to $60 \%$ reduction in the dose of ICS among adult participants with well-controlled asthma. The duration of treatment ranged from 12 to 52 weeks (mean duration 21 weeks; median duration 14 weeks). Two studies were performed in the setting of primary care, two were performed in the secondary care setting and two provided no information on setting.

Meta-analysis was hampered by the small number of studies that contributed to each comparison, combined with differences among outcomes reported in the included studies. However, a low level of heterogeneity was observed in the meta-analyses that 
were performed. We found no statistically significant differences between groups (step-down of ICS vs no change in ICS) with respect to any of the primary or secondary outcomes considered in this review and thus were unable to determine whether stepping down the dose of ICS in adults with asthma (compared with maintaining the previous dose of ICS) confers overall benefit. On one hand, we did not identify a statistically significant between-group difference for measures of effectiveness such as asthma control, lung function or the number of participants experiencing exacerbations, which would support the guideline-recommended use of an ICS dose reduction for patients with well-controlled asthma. However, we noted a numerical trend towards a greater number of participants experiencing exacerbations, and we observed no benefit in terms of other safety outcomes. Moreover, we rated the quality of the evidence as generally low or very low, which means that we cannot be confident in the effect estimates (see below). Finally, whether concomitant treatment with a LABA influences the benefit/harm ratio for stepping down ICS remains unclear.

\section{Overall completeness and applicability of evidence}

Two of the included studies were performed in the primary care setting, two in the secondary care setting and in two cases the setting was not reported. Each comparison ( \pm LABA) included one study in each of these three categories (primary care, secondary care, not stated); however, owing to the small number of studies contributing to each outcome, some outcomes may have been more representative of a particular setting. When this was the case, we accounted for this factor by downgrading the quality of the evidence for indirectness. Furthermore, single studies (representative of a single regimen or treatment duration) contributed to several of the outcomes, and most of the metaanalyses comprised only two studies. Therefore, our results may be relevant to the particular treatment regimens represented in the individual studies. Finally, our results are relevant only to adult patients. It is possible that potential harms due to systemic effects associated with long-term ICS use might be more relevant to children. To examine this, we would need to consider including paediatric studies in future iterations of this review, or in a separate review.

One of the concerns associated with stepping down the dose of ICS in patients with well-controlled asthma is possible slow deterioration in asthma control over time as bronchial hyperresponsiveness slowly returns. Moreover, long-term exposure to steroids may result in the development of systemic side effects such as loss of bone density in adults and growth retardation in children (Colice 2006; Lipworth 1999; SIGN/BTS 2016). The mean duration of the included studies was 21 weeks (median duration 14 weeks), which is potentially insufficient for detecting long-term deterioration in asthma control/lung function or for adequately assessing long-term safety outcomes.

\section{Quality of the evidence}

Few relevant studies met the prespecified criteria for inclusion; this fact, combined with the use of varied outcome measures across included studies, limited the number of meta-analyses that we could perform. In terms of risk of bias, the included studies were generally of moderate quality, although selective reporting introduced risk of bias in five out of six included studies. Furthermore, it was not clear whether adequate methods of randomisation sequence generation or concealment of allocation were used in all but one study.

We assessed the quality of evidence in this review using GRADE (Higgins 2011) and GRADEpro software; our findings in the 'Summary of findings tables'. Summary of findings for the main comparison presents our findings for the first comparison (stepping down ICS vs no change in ICS, in patients not receiving a concomitant $\mathrm{LABA}$ ), and Summary of findings 2 presents our findings for the second comparison (stepping down ICS vs no change in ICS, in patients receiving a concomitant LABA). In summary, for both comparisons, we assessed the quality of the synthesised evidence as low or very low for most outcomes because of risk of bias (principally, selective reporting), imprecision (few events in a small number of studies, or wide confidence intervals) and indirectness (single studies representative of a single setting or drug regimen). Based on the quality of the evidence, we cannot be confident about the effect estimates presented in this review.

\section{Potential biases in the review process}

We followed standard procedures as described in the Cochrane Handbook for Systematic Reviews of Interventions (Higgins 2011) to minimise bias in the review process. With regard to the search process, the Cochrane Airways Group Information Specialist designed and conducted the main electronic search, two review authors independently sifted the search results and two review authors (one with expert clinical knowledge) reviewed the full-text results. Consistent with Cochrane methods, we excluded no trials on the basis of language, publication status or outcomes reported, so we are confident that we identified all potentially relevant evidence from RCTs. In terms of our findings and conclusions, two review authors independently performed all steps in the review process for which a subjective decision was required (e.g. selection of studies, extraction of data, assessment of risk of bias, assessment of the overall quality of evidence using GRADE), and, if necessary, a third review author assisted in resolving disagreements. Finally, this review has undergone editorial and peer review such that the opinion of independent external experts has been considered. Together, these factors should ensure that our conclusions fairly represent the results synthesised during the review process.

\section{Agreements and disagreements with other studies or reviews}

Our findings agree well with those of a systematic review (Gionfriddo 2015) that examined the evidence for stepping down the dose of ICS from a scheduled regimen to an as-needed basis. Those review authors found insufficient evidence to associate stepping down ICS dose with an effect on the number of asthma exacerbations. In contrast, the authors found some evidence for fewer symptom-free days in patients who used an ICS on an asneeded basis. In another systematic review, Hagan and colleagues similarly found that asthma exacerbations were statistically no more likely among individuals who reduced ICS than among those who maintained their ICS dose (Hagan 2014). The Hagan review included studies of both adults and children and permitted stepdown to ICS on an as-needed basis. Nevertheless, their findings are consistent with those of our review. 


\section{AUTHORS' CONCLUSIONS}

\section{Implications for practice}

The effect of reducing ICS dose, in the presence or absence of a LABA, on exacerbations and disease control in asthma remains unknown. In addition, whether this strategy impacts quality of life, hospitalisations and adverse events (steroid related or otherwise) is unclear.

\section{Implications for research}

In light of considerable uncertainty around effect estimates, in particular for outcomes related to long-term safety, additional welldesigned RCTs are required to examine safety and effectiveness in patients who step down their dose of ICS compared with those who maintain their existing dose. It would be prudent for future trials to use validated measures to examine asthma control (e.g. Asthma Control Score) and health-related quality of life (e.g. Asthma Quality of Life Questionnaire). Future trials ideally should last longer than six months (substantially longer periods would be beneficial), first, to permit adequate monitoring of safety outcomes, in particular, of potential systemic effects associated with long-term use of ICS, and second, to ensure that slow deterioration of asthma control/lung function does not occur over time. Measurement of airway hyperresponsiveness or airway inflammation at baseline and during follow-up may serve to explain why the condition of some patients deteriorates, and others maintain control on lower doses.

\section{ACKNOWLEDGEMENTS}

The Background and Methods sections of this review are based on a standard template used by the Cochrane Airways Review Group. Thank you to Elizabeth Stovold for assisting with the search strategy, and to Chris Cates, Emma Welsh, Sally Spencer and Steve Milan for providing advice and support.

Rebecca Normansell was the Editor for this review and commented critically on the review.

The National Institute for Health Research (NIHR) is the largest single funder of the work carried out by the Cochrane Airways Review Group. The views and opinions expressed therein are those of the review authors and do not necessarily reflect those of the NIHR, the National Health Service or the Department of Health. 


\section{R E F E R E N C E S}

\section{References to studies included in this review}

Godard 2008 \{published data only\}

Godard P, Attali V. Comparison of different treatment strategies in stepping down combination treatment withdrawing the LABA versus reducing the ICS dose [Abstract]. Proceedings of the American Thoracic Society. 2006:A213.

Godard P, Greillier P, Pigearias B, Nachbaur G, Desfougeres J$\mathrm{L}$, Attali V. Maintaining asthma control in persistent asthma: comparison of three strategies in a 6-month double-blind randomised study. Respiratory Medicine 2008;102(8):1124-31.

\section{Gunn 1997 \{published data only\}}

Gunn SD, Choudhury M, Au K, Burnett RJ, Black HL, Turbitt ML. Inhaled steroid treatment reduction in stable asthmatics: a comparison of beclomethasone/budesonide metered dose inhaler with half dose treatment using budesonide Turbohaler, given once or twice daily. British Journal of Clinical Research 1997;8:67-80.

\section{Hawkins 2003 \{published data only\}}

Hawkins G, McMahon AD, Twaddle S, Wood SF, Ford I, Thompson NC. Stepping down inhaled corticosteroids in asthma: a randomised controlled trial. Thorax 2002;57(Suppl III):iii11.

Hawkins G, McMahon AD, Twaddle S, Wood SF, Ford I, Thomson NC, et al. Stepping down inhaled corticosteroids in asthma: randomised controlled trial. BMJ 2003;326(7399):1115-8

See S, Rubin S. Tapering inhaled steroids effective for chronic asthma. Journal of Family Practice 2003;52(10):748-51.

\section{Juniper 1991 \{published data only\}}

Juniper EF, Kline PA, Vanzieleghem MA, Hargreave FE. Reduction of budesonide after a year of increased use: a randomised controlled trial to evaluate whether improvements in airway responsiveness and clinical asthma are maintained. Journal of Allergy and Clinical Immunology 1991;87(2):483-9.

\section{Knox 2007 \{published data only\}}

Knox A, Langan J, Martinot JB, Gruss C, Höfner D. Comparison of a step-down dose of once-daily ciclesonide with a continued dose of twice-daily fluticasone propionate in maintaining control of asthma. Current Medical Research Opinion 2007;23(10):2387-94.

\section{Magnussen 2000 \{published data only\}}

Magnussen $\mathrm{H}$, Magnussen $\mathrm{H}$, Comparative Inhaled Steroid Investigation Group CISIG. Equivalent asthma control after dose reduction with HFA-134a beclomethasone solution aerosol. Respiratory Medicine 2000;94(6):549-55.

\section{References to studies excluded from this review}

Aalbers 2004 \{published data only\}

Aalbers R. Fixed or adjustable maintenance-dose budesonide/ formoterol compared with fixed maintenance-dose salmeterol/ fluticasone propionate in asthma patients aged [greater-than or equal to] 16 years: post hoc analysis of a randomized, doubleblind open-label extension, parallel-group study. Clinical Drug Investigation 2010;30(7):439-51.

Aalbers R, Backer V, Kava TT, Omenaas ER, Sandström T, Jorup C, et al. Adjustable maintenance dosing with budesonide/ formoterol compared with fixed-dose salmeterol/fluticasone in moderate to severe asthma. Current Medical Research Opinion 2004;20(2):225-40.

Aalbers R, Harris A, Naya I. Adjustable dosing with budesonide/ formoterol achieves sustained guideline 'well-controlled asthma' following step down in treatment [Abstract]. European Respiratory Journal. 2005; Vol. 26:Abstract No. 431.

\section{Adachi 2001 \{published data only\}}

Adachi M, Kohno Y, Minoguchi K, Yasurou K, Kochno Y. Step-down and step-up therapy in moderate persistent asthma. International Archives of Allergy and Immunology 2001;124(1-3):414-6

\section{ALA 2007 \{published data only\}}

The American Lung Association Asthma Clinical Research Centers. Randomized comparison of strategies for reducing treatment in mild persistent asthma. New England Journal of Medicine 2007;356(20):2027-39.

\section{Anonymous 1979 \{published data only\}}

Anonymous. Double-blind trial comparing two dosage schedules of beclomethasone dipropionate aerosol with a placebo in chronic bronchial asthma. Second report of the Brompton Hospital/Medical Research Council Collaborative Trial. British Journal of Diseases of the Chest 1979;73(2):121-32.

Baba 1999 \{published data only\}

Baba K, Hattori T, Sakakibara A, Kobayashi T, Takagi K. The usefulness of pranlukast or seratrodast for step-down of inhaled corticosteroid therapy in adult chronic asthma. American Journal of Respiratory and Critical Care Medicine 1999;159(3; Part 2 of 2):A626.

\section{Baba 2000 \{published data only\}}

Baba K, Hattori T, Koishikawa I, Yoshida K, Kobayashi T, Takagi K. Serum eosinophil cationic protein for predicting the prognosis of a step-down in inhaled corticosteroid therapy in adult chronic asthmatics. Journal of Asthma 2000;37(5):399-408.

\section{Bateman 2005 \{published data only\}}

Bateman E, Atienza T, Mihaescu T, Duggan M, Jacques L, Goldfrad C. Asthma control is maintained if treatment with fluticasone propionate/salmeterol (FSC; advair/seretide) is stepped down [Abstract]. American Thoracic Society 2005 International Conference. 2005:C12. 
Bateman ED, Jacques L, Goldfrad C, Atienza T, Mihaescu T, Duggan M. Asthma control can be maintained when fluticasone propionate/salmeterol in a single inhaler is stepped down. Journal of Allergy and Clinical Immunology 2006;117(3):563-70.

Belda 2006 \{published data only\}

Belda J, Parameswaran K, Lemiere C, Kamada D, O'Byrne PM, Hargreave FE. Predictors of loss of asthma control induced by corticosteroid withdrawal. Canadian Respiratory Journal 2006;13(3):129-33.

Boulet 1990 \{published data only\}

Boulet LP, Cartier A, Cockcroft DW, Gruber JM, Laberge F, MacDonald GF, et al. Tolerance to reduction of oral steroid dosage in severely asthmatic patients receiving nedocromil sodium. Respiratory Medicine 1990;84(4):317-23.

\section{Brambilla 1994 \{published data only\}}

Brambilla C, Godard P, Lacronique J, Allaert FA, Duroux P, Blaive $B$, et al. A 3-month comparative dose-reduction study with inhaled beclomethasone dipropionate and budesonide in the management of moderate to severe adult asthma. Drug Investigation 1994;8(1):49-56.

\section{Britton 1997 \{published data only\}}

Britton MG, Bone MF, Boyd G, Catterall JR, Ward MJ, Richards K. Comparison of a lower fixed dose of inhaled fluticasone propionate FP with a high dose step-down regimen of FP in the prevention of re-exacerbations after an acute severe attack of asthma requiring oral corticosteroid therapy. Thorax 1997;52(Suppl 6):A1/S3.

\section{Bruggenjurgen 2005 \{published data only\}}

Bruggenjurgen B, Selim D, Kardos P, Richter K, Vogelmeier C, Roll $S$, et al. Economic assessment of adjustable maintenance treatment with budesonide/formoterol in a single inhaler versus fixed treatment in asthma. Pharmacoeconomics 2005;23(7):723-31.

\section{Busse 2003 \{published data only\}}

Busse W, Koenig SM, Oppenheimer J, Sahn SA, Yancey SW, Reilly $\mathrm{D}$, et al. Steroid-sparing effects of fluticasone propionate 100 microg and salmeterol 50 microg administered twice daily in a single product in patients previously controlled with fluticasone propionate 250 microg administered twice daily. Journal of Allergy and Clinical Immunology 2003;111(2):57-65.

\section{Campbell 1998 \{published data only\}}

Campbell LM, Gooding TN, Aitchison WR, Smith N, Powell JA. Initial loading (400 micrograms twice daily) versus static (400 micrograms nocte) dose budesonide for asthma management. PLAN Research Group. International Journal of Clinical Practice 1998;52(6):361-8, 370.

\section{Casale 2003 \{published data only\}}

Casale TB, Nelson HS, Kemp J, Parasuraman B, Uryniak T, Liljas B. Budesonide Turbuhaler delivered once daily improves health-related quality of life and maintains improvements with a stepped-down dose in adults with mild to moderate asthma. Annals of Allergy, Asthma \& Immunology 2003;90(3):323-30.
Chanez 2001 \{published data only\}

Chanez P, Karlstrom R, Godard P. High or standard initial dose of budesonide to control mild-to-moderate asthma?. European Respiratory Journal 2001;17(5):856-62.

\section{Chiu 2011 \{published data only\}}

Chiu K-C, Hsu J-Y, Lin M-S, Liu W-T, Wang C-H, Kuo H-P. Comparison of the efficacy of cicleosonide with budesonide in mild to moderate asthma patients after step-down therapy [Abstract]. European Respiratory Society Annual Congress. 2011; Vol. 38:721s [P3965].

Chiu KC, Chou YL, Hsu JY, Lin MS, Lin CH, Chou PC, et al. Comparison of the efficacy of ciclesonide with that of budesonide in mild to moderate asthma patients after stepdown therapy: a randomised parallel-group study. NPJ Primary Care Respiratory Medicine 2014;24:14010.

\section{Chung 2002 \{published data only\}}

Chung KF, Holgate S, O'Brien J, Fox H, Thirlwell J. Inhaled corticosteroid dose reducing effect of amalizumab in patients with controlled, severe asthma according to usage of inhaled long acting beta agonists [Abstract]. Journal of Allergy, Asthma and Immunolgy 2002;109(Suppl 1):Abstract No: 726.

\section{Davies 1977 \{published data only\}}

Davies G, Thomas P, Broder I, Mintz S, Silverman F, Leznoff A, et al. Steroid-dependent asthma treated with inhaled beclomethasone dipropionate. A long-term study. Annals of Internal Medicine 1977;86(5):549-53.

\section{Dorinsky 2003 \{published data only\}}

Dorinsky P, Stauffer J, Waitkus-Edwards K, Yancey S, Prillaman BA, Sutton L. "Stepping down" from fluticasone propionate/salmeterol 100/50mcg diskus results in loss of asthma control [Abstract]. European Respiratory Journal 2004;24(Suppl 48):309s.

Dorinsky P, Yancey S, Reilly D, Stauffer J, Edwards L, Sutton L. Control of airway inflammation is maintained in asthma patients following a reduction in ICS dose with fluticasone propionate/salmeterol (FSC) compared with higher dose fluticasone propionate (FP) alone [Abstract]. European Respiratory Journal. 2004; Vol. 24:308s.

Dorinsky PM, Stauffer J, Waitkus-Edwards K, Yancey S, Prillaman BA, Sutton L. "Stepping down" from fluticasone propionate/salmeterol 100/50mcg Diskus(R) results in loss of asthma control: lack of effect of ethnic origin [Abstract]. Chest 2004;126(4 Suppl):758S-a.

Dorinsky PM, Yancey SW, Reilly D, Edwards L. The effectiveness of fluticasone propionate/salmeterol 100/50mcg Diskus(R) (FSC) as an inhaled corticosteroid-sparing agent: effect of baseline asthma severity [Abstract]. Chest. 2003; Vol. 124:87S-b, 88.

Dorinsky PM, Yancey SW, Waitkus-Edwards K, Edwards L, Dorinsky PM, Yancey SW, et al. Clinical markers of worsening asthma with the fluticasone propionate/salmeterol 100/50 mcg Diskus(R) (FSC) vs fluticasone propionate (FP) $250 \mathrm{mcg}$ alone in patients requiring FP $250 \mathrm{mcg}$ BID for asthma stability [Abstract]. Chest 2003;124(4):88S. 
Oppenheimer J, Stauffer J, Waitkus-Edwards K, Yancey S, Prillaman B, Sutton L, et al. 'Stepping down' from fluticasone propionate/salmeterol $100 / 50 \mathrm{mcg}$ diskus results in loss of asthma control [Abstract]. American Thoracic Society 100th International Conference. 2004:A37 Poster J94.

\section{Fardon 2005 \{published data only\}}

Fardon TC, Haggart K, Lee DKC, Lipworth BJ. Stepping down inhaled corticosteroids in severe asthma with long acting bronchodilators utilising effort dependent and independent measures of pulmonary function [Abstract]. American Thoracic Society 2005 International Conference. 2005:[B35] [Poster: G3].

\section{Fardon 2007 \{published data only\}}

Fardon T, Haggart K, Lee DKC, Lipworth BJ. A proof of concept study to evaluate stepping down the dose of fluticasone in combination with salmeterol and tiotropium in severe persistent asthma. Respiratory Medicine 2007;101(6):1218-28.

\section{FitzGerald 2003 \{published data only\}}

FitzGerald JM, Sears MR, Boulet LP, Becker AB, Mclvor AR, Ernst $P$, et al. Adjustable maintenance dosing with budesonide/ formoterol reduces asthma exacerbations compared with traditional fixed dosing: a five-month multicentre Canadian study. Canadian Respiratory Journal 2003;10(8):427-34.

FitzGerland JM, Sears MR, Boulet LP, Becker AB, Boulet L-P, Becker AB. Erratum: Adjustable maintenance dosing with budesonide/formoterol reduces asthma exacerbations compared with traditional fixed dosing: a five month multicentre Canadian study [Canadian Respiratory Journal (2003) vol. 10 (8) (427-434)]. Canadian Respiratory Journal 2004;11(1):20.

\section{FitzGerald 2005 \{published data only\}}

FitzGerald JM, Boulet LP, Follows RMA. The CONCEPT trial: a 1-year, multicenter, randomized, double-blind, doubledummy comparison of a stable dosing regimen of salmeterol/ fluticasone propionate with an adjustable maintenance dosing regimen of formoterol/ budesonide in adults with persistent asthma. Clinical Therapeutics 2005;27(4):393-406.

Price DB, Williams AE, Yoxall S. Salmeterol/fluticasone stabledose treatment compared with formoterol/budesonide adjustable maintenance dosing: impact on health-related quality of life. Respiratory Research 2007;8:46.

\section{FLIQ96 2005 \{published data only\}}

FLIQ96 GlaxoSmithKline. Effect of fourteen weeks treatment with fluticasone propionate step-down dosing from $1000 \mathrm{mcg} /$ day in comparison with a fixed dose of $200 \mathrm{mcg} /$ day followed by an open phase with placebo administered for 8 weeks in subjects with mild asthma who exacerbate during treatment with beta-2 agonist (prn). GlaxoSmithKline Clinical Study Register 2005.

\section{Fowler 2002 \{published data only\}}

Fowler S, Currie GP, Lipworth BJ. Step down therapy for asthma with inhaled steroids alone or in combination with a long acting beta2 agonist [Abstract]. Journal of Allergy, Asthma and Immunolgy 2002;109(Suppl 1):Abstract No: 745.
Haggart 2004 \{published data only\}

Haggart K, Fardon TC, Lee DKC, Lipworth BJ. Stepping down inhaled steroids in severe asthma with long acting bronchodilators: utilising effort dependent and independent measures of pulmonary function [Abstract]. Thorax 2004;59(Suppl II):ii72.

\section{Hamada 2008 \{published data only\}}

Hamada K, Yasuba H, Tanimura K, Hiramatu M, Kobayashi Y, Kita H. How can we stop ICS? Risk control therapy by as needed inhaled fluticasone after stepping down [Abstract]. Journal of Allergy and Clinical Immunology. 2008; Vol. 121:S219 [844].

\section{Kardos 2001 \{published data only\}}

Kardos P, Brüggenjürgen B, Martin A, Meyer-Sabellek W, Richter K, Vogelmeier C, et al. Treatment of bronchial asthma using a new adjustable combination treatment plan: Asthma Control Plan (ATACO) [German]. Pneumologie 2001;55(5):253-7.

\section{Kawagishi 2000 \{published data only\}}

Kawagishi Y, Oosaki R, Kashii T, Kawasaki A, Fujishita T, Arai N, et al. Long-term prognosis of asthmatic patients treated with lowdose beclomethasone dipropionate. Arerugi 2000;49(5):391-6.

\section{Keonig 2004 \{published data only\}}

Keonig S, Waitkus-Edwards K, Yancey S, Prillman B, Dorinsky P, Prillaman $B$. Loss of asthma control when patients receiving fluticasone propionate/salmeterol 100/50 $\mu$ g Diskus are "stepped-down" to fluticasone propionate, salmeterol or montelukast alone [Abstract]. Journal of Allergy and Clinical Immunology. 2004; Vol. 113:S94.

\section{Massanari 2008 \{published data only\}}

Massanari M, Jimenez P, Kianifard F, Maykut R, Zeldin R. The omalizumab associated decrease in peripheral blood eosinophils in moderate severe IgE mediated asthma is sustained following inhaled steroid dose reduction [Abstract]. American Thoracic Society International Conference. 2008:A105.

\section{McKinlay 2011 \{published data only\}}

McKinlay L, Williamson PA, Short PM, Fardon TC, Lipworth BJ. Proof of concept study to evaluate step-down therapy with inhaled corticosteroid alone or additive therapy on surrogate inflammatory markers in asthma. British Journal of Clinical Pharmacology 2011;71(1):128-31.

\section{Mikloweit 2000 \{published data only\}}

Mikloweit P, Zachgo W, Hader S, Reiss Plagemann C, Grimm A, Drews $G$. Lung function before and 12 weeks after switching to a reduced dose of HFA-beclomethasone dipropionate. American Journal of Respiratory and Critical Care Medicine 2000;161(3 Suppl):A186.

\section{Obase 2013 \{published data only\}}

Obase Y, Ikeda M, Kurose K, Abe M, Shimizu H, Ohue Y, et al. Step-down of budesonide/formoterol in early stages of asthma treatment leads to insufficient anti-inflammatory effect. Journal of Asthma 2013;50(7):718-21. 
Paggiaro 2011 \{published data only\}

Paggiaro P, Nicolini G, Crimi N, Fabbri L, Olivieri D, Rossi A, et al. Six months step down treatment from high dose ICS/LABA combination therapy in asthma [Abstract]. American Journal of Respiratory and Critical Care Medicine. 2011; Vol. 183:A1278.

Paggiaro P, Nicolini G, Crimi N, Fabbri LM, Olivieri D, Rossi A, et al. Asthma control and lung function after step down from high dose ICS/LABA combination therapy [Abstract]. European Respiratory Society Annual Congress. 2011; Vol. 38:722s [P3967].

\section{Reddel 2007 \{published data only\}}

Reddel HK, Peyters MJ, Wark PA, Sand IB, Jenkins CR. Comparison of the efficacy of seretide and flixotide when downtitrating the inhaled corticosteroid dose [Abstract]. Respirology. (Carlton, Vic.), 2007; Vol. 12:A40.

\section{Rumbak 1998 \{published data only\}}

Rumbak M, Self T, Kelso T, Eberle L, Abou-Shala N, Learned S, et al. Moderate to high dose inhaled corticosteroids in adult asthmatics: does salmeterol facilitate step down therapy? [Abstract]. European Respiratory Journal. 1998; Vol. 12:19s, P157.

\section{Schmier 2003 \{published data only\}}

Schmier J, Leidy NK, Gower R. Reduction in oral corticosteroid use with mometasone furoate dry powder inhaler improves health-related quality of life in patients with severe persistent asthma. Journal of Asthma 2003;40(4):383-93.

\section{Shamsul 2007 \{published data only\}}

Shamsul AI, Hadzri HM, Noradina AT, Fauzi MA, Hamid AJ, Rosalina AM, et al. Step-down approach in chronic stable asthma; a comparison of reducing dose inhaled formoterol/ budesonide with maintaining inhaled budesonide [Abstract]. Respirology. (Carlton, Vic.), 2007; Vol. 12:A141.

\section{Ställberg 2003 \{published data only\}}

Ställberg B, Olsson P, Jörgensen LA, Lindarck N, Ekström T. Budesonide/formoterol adjustable maintenance dosing reduces asthma exacerbations versus fixed dosing. International Journal of Clinical Practice 2003;57(8):656-61.

\section{Additional references}

\section{Adams 2005}

Adams NP, Bestall JB, Malouf R, Lasserson TJ, Jones PW. Beclomethasone versus placebo for chronic asthma. Cochrane Database of Systematic Reviews 2005, Issue 1. [DOI: 10.1002/14651858.CD002738]

\section{Adams 2008}

Adams N, Bestall J, Lasserson TJ, Jones PW, Cates CJ. Fluticasone versus placebo for chronic asthma in adults and children. Cochrane Database of Systematic Reviews 2008, Issue 4. [DOI: 10.1002/14651858.CD003135.pub4]

\section{Ahmad 2015}

Ahmad S. Stopping long-acting beta 2 -agonists (LABA) for adults with asthma well controlled by LABA and inhaled corticosteroids. Cochrane Database of Systematic Reviews 2015, Issue 6. [DOI: 10.1002/14651858.CD011306.pub2]

\section{Bateman 2004}

Bateman ED, Boushey HA, Bousquet J, Busse WW, Clark TJ, Pauwels RA, et al. Can guideline-defined asthma control be achieved? The Gaining Optimal Asthma ControL study. American Journal of Respiratory and Critical Care Medicine 2004;170:836-44.

\section{Bateman 2008}

Bateman ED, Hurd SS, Barnes PJ, Bousquet J, Drazen JM, FitzGerald M, et al. Global strategy for asthma management and prevention: GINA executive summary. European Respiratory Journal 2008;31(1):143-78.

\section{Colice 2006}

Colice GL. New developments in inhaled corticosteroids. Allergy and Asthma Proceedings 2006;27(5):332-40.

\section{Custovic 2012}

Custovic A, Simpson A. The role of inhalant allergens in allergic airways disease. Journal of Investigational Allergology and Clinical Immunology 2012;22(6):393-401.

\section{Ducharme 2010}

Ducharme FM, Ni Chroinin M, Greenstone I, Lasserson, TJ. Addition of long-acting beta2-agonists to inhaled steroids versus higher dose inhaled steroids in adults and children with persistent asthma. Cochrane Database of Systematic Reviews 2010, Issue 4. [DOI: 10.1002/14651858.CD005533.pub2]

\section{Fisseler-Eckhoff 2011}

Fisseler-Eckhoff A, Bartsch H, Zinsky R, Schirren J. Environmental isocyanate-induced asthma: morphologic and pathogenetic aspects of an increasing occupational disease. International Journal of Environmental Research and Public Health 2011;8(12):3672-87.

\section{GINA 2016}

Global Initiative for Asthma (GINA). From the Global Strategy for Asthma Management and Prevention, 2016. www.ginasthma.org (accessed 19 October 2016).

\section{Gionfriddo 2015}

Gionfriddo MR, Hagan JB, Hagan CR, Volcheck GW, CastanedaGuarderas A, Rank MA. Stepping down inhaled corticosteroids from scheduled to as needed in stable asthma: systematic review and meta-analysis. Allergy and Asthma Proceedings 2015;36(4):262-7.

\section{Global Asthma Network 2014}

Global Asthma Network. The Global Asthma Report 2014. http:// www.globalasthmareport.org/resources/Global_Asthma Report_2014.pdf (accessed 16 April 2015). 


\section{Hagan 2014}

Hagan JB, Samant SA, Volcheck GW, Li JT, Hagan CR, Erwin PJ, et al. The risk of asthma exacerbation after reducing inhaled corticosteroids: a systematic review and meta-analysis of randomized controlled trials. Allergy 2014;69(4):510-6.

\section{Higgins 2011}

Higgins JPT, Green S (editors). Cochrane Handbook for Systematic Reviews of Interventions Version 5.1.0 [updated March 2011]. The Cochrane Collaboration, 2011. www.cochranehandbook.org.

\section{Jaakkola 2008}

Jaakkola JJ, Knight TL. The role of exposure to phthalates from polyvinyl chloride products in the development of asthma and allergies: a systematic review and meta-analysis. Environmental Health Perspectives 2008;116(7):845-53.

\section{Juniper 1990}

Juniper EF, Kline PA, Vanzieleghemt MA, Ramsdale EH, O'Byrnett PM, Hargreave FE. Long-term effects of budesonide on airway responsiveness and clinical asthma severity in inhaled steroid-dependent asthmatics. European Respiratory Journal 1990;3:1122-7.

\section{Juniper 1993}

Juniper EF, Guyatt GH, Ferrie PJ, Griffith LE. Measuring quality of life in asthma. American Review of Respiratory Disease 1993;147:832-8.

\section{Kew 2013}

Kew KM, Karner C, Mindus SM, Ferrara G. Combination formoterol and budesonide as maintenance and reliever therapy versus combination inhaler maintenance for chronic asthma in adults and children. Cochrane Database of Systematic Reviews 2013, Issue 12. [DOI: 10.1002/14651858.CD009019.pub2]

\section{Kew 2015}

Kew KM, Beggs S, Ahmad S. Stopping long-acting beta2-agonists ( $L A B A$ ) for children with asthma well controlled on LABA and inhaled corticosteroids. Cochrane Database of Systematic Reviews 2015, Issue 5. [DOI: 10.1002/14651858.CD011316.pub2]

\section{Lipworth 1992}

Lipworth BJ, McDevitt DG. Inhaled 2-adrenoceptor agonists in asthma: help or hindrance?. British Journal of Clinical Pharmacology 1992;33:129-38.

\section{Lipworth 1999}

Lipworth BJ. Systemic adverse effects of inhaled corticosteroid therapy: a systematic review and meta-analysis. Archives of Internal Medicine 1999;159(9):941-55.

\section{CHARACTERISTICS OF STUDIES}

Characteristics of included studies [ordered by study ID]

\section{NHS 2013}

National Health Service. Respiratory National Charts NHS Business Services Authority. October 2013. http:// www.nhsbsa.nhs.uk/PrescriptionServices/Documents/ PPDPrescribingAnalysisCharts/Resp_Oct_2013_National.pdf (accessed 14 April 2015)

\section{Partridge 2006}

Partridge MR, van der Molen T, Myrseth SE, Busse WW. Attitudes and actions of asthma patients on regular maintenance therapy: the INSPIRE study. BMC Pulmonary Medicine 2006;6(13):1-9.

\section{Pearce 1999}

Pearce N, Pekkanen J, Beasley R. How much asthma is really attributable to atopy?. Thorax 1999;54(3):268-72.

\section{Review Manager 2014 [Computer program]}

The Nordic Cochrane Centre, The Cochrane Collaboration. Review Manager (RevMan). Version 5.3. Copenhagen: The Nordic Cochrane Centre, The Cochrane Collaboration, 2014.

\section{Rimmington 1997}

Rimmington LD, Aronoffsky L, Mowatt A, Wharburton E, Ryland I, Pearson MG. Use of a simple patient focused asthma morbidity score. European Respiratory Journal 1997;11:1289.

\section{Rogers 2012}

Rogers L, Reibman J. Stepping down asthma treatment: how and when. Current Opinion in Pulmonary Medicine 2012;18(1):70-5.

\section{SIGN/BTS 2016}

Scottish Intercollegiate Guidelines Network/British Thoracic Society. British guideline on the management of asthma. A national clinical guideline. Edinburgh/London: SIGN/BTS, 2016. [ISBN 9781909103474 ]

\section{Tse 1984}

Tse CS, Bernstein IL. Corticosteroid aerosols in the treatment of asthma. Pharmacotherapy 1984;4(6):334-42.

\section{WHO 2014}

World Health Organization. Adolescents: health risks and solutions. Fact sheet $\mathrm{N}^{\circ} 345$. Updated May 2014. http:// www.who.int/mediacentre/factsheets/fs345/en/ (accessed on 10 June 2015).

\section{Xepapadaki 2009}

Xepapadaki P, Manios Y, Liarigkovinos T, Grammatikaki E, Douladiris N, Kortsalioudaki C, et al. Association of passive exposure of pregnant women to environmental tobacco smoke with asthma symptoms in children. Pediatric Allergy and Immunology 2009;20:423-9. 


\section{Methods}

Study design: randomised controlled trial

Total duration of study: 24 weeks.

'Run-in' period: 8 weeks. All participants received salmeterol/fluticasone propionate combination (SFC) at a dose of $50 / 250 \mu \mathrm{g}$ twice daily.

Number of study centres and locations: 124 centres (no locations specified)

Study setting: not stated

Date of study: not stated

Participants

Randomised (n): 475 (SFC 50/250, $n=159 ;$ SFC 50/100, $n=157 ;$ FP 250, $n=159$ )

Analysed (n): 464 (SFC 50/250, $n=154 ;$ SFC 50/100, $n=156 ;$ FP 250, $n=154$ )

Withdrawals (n): 63

Median age (range), years: SFC 50/250, 46.5 (18-81); SFC 50/100, 43.0 (18-75); FP 25042.0 (18-77)

Age range, years: $18-81$

Gender (\% female): SFC 50/250, 48.1; SFC 50/100, 46.2; FP 25051.3

Severity of condition: well controlled on step 2 or 3 . Mean \% predicted prebronchodilator FEV 1 (SD) as follows: SFC 50/250, 87.8 (18.2); SFC 50/100, 91.2 (17.8); FP 250, 90.8 (17.2)

Diagnostic criteria: Asthma control was assessed using the GOAL definitions of 'well controlled' and 'total control'.

Baseline lung function (mean morning PEF (SD), L/min): SFC 50/250, 465.6 (113.2); SFC 50/100, 467.9 (111.2); FP 250, 463.7 (105.1)

Smoking history, \% smokers or ex-smokers: SFC 50/250, 24.7; SFC 50/100, 21.3; FP 250, 16.2

Inclusion criteria: aged $\geq 18$ years; documented history of asthma ( $\geq 6$ months) well controlled with current treatment (ICS at a dose of CFC beclomethasone dipropionate or equivalent and a long-acting beta $_{2}$-agonist at recommended dose) at a stable dose for $\geq 4$ weeks before initial clinic visit (V1); respiratory tract infection, with acute exacerbation requiring emergency department treatment/hospitalisation or use of oral/parenteral steroids, within 4 weeks of V1; any change in asthma maintenance treatment within 4 weeks

Exclusion criteria: smoking history $\geq 10$ pack-years; respiratory tract infection

Details of criteria for stepping down treatment: All participants received SFC 50/250 $\mu \mathrm{g}$ twice daily and were randomised to remain on SFC 50/250 or move to 1 of the 2 step-down treatment arms if their asthma was assessed as 'well controlled' over the last 2 weeks of the run-in period; asthma control was assessed according to GOAL definitions (see Bateman 2004).

Interventions

Intervention 1: SFC 50/100 $\mu \mathrm{g}$ twice daily

Intervention 2: FP $250 \mu \mathrm{g}$ twice daily (not relevant to review)

Comparison: SFC 50/250 $\mu \mathrm{g}$ twice daily

Concomitant medications: Short-acting bronchodilators (previously used as rescue medication) and antihistamines were permitted, provided they had been used for at least 4 weeks.

Excluded medications: All previous asthma medications were discontinued at entry into the run-in period, except short-acting bronchodilators (previously used as rescue medication) and antihistamines, provided they had been used for at least 4 weeks. 
Godard 2008 (Continued)

Outcomes

Primary outcomes: mean morning PEF over the first 12 weeks of randomised treatment

Secondary outcomes: mean morning PEF over the last 12 weeks of randomised treatment; daily symptoms; use of short-acting bronchodilator as rescue medication; $\mathrm{FEV}_{1}$; asthma control based on GOAL definitions of total control and 'well-controlled' (see Bateman 2004)

Notes

Funding for trial: not stated

Notable conflicts of interest of trial authors: Three of the trial authors had received sponsorship and had attended advisory boards for various pharmaceutical companies, including AstraZeneca, GlaxoSmithKline and Boehringer-Ingelheim; 3 authors are employees of GlaxoSmithKline.

\section{Risk of bias}

\begin{tabular}{|c|c|c|}
\hline Bias & Authors' judgement & Support for judgement \\
\hline $\begin{array}{l}\text { Random sequence genera- } \\
\text { tion (selection bias) }\end{array}$ & Unclear risk & Insufficient information provided \\
\hline $\begin{array}{l}\text { Allocation concealment } \\
\text { (selection bias) }\end{array}$ & Unclear risk & Insufficient information provided \\
\hline $\begin{array}{l}\text { Blinding of participants } \\
\text { and personnel (perfor- } \\
\text { mance bias) } \\
\text { All outcomes }\end{array}$ & Low risk & Study reported as double blind \\
\hline $\begin{array}{l}\text { Blinding of outcome as- } \\
\text { sessment (detection bias) } \\
\text { All outcomes }\end{array}$ & Low risk & Study reported as double blind \\
\hline $\begin{array}{l}\text { Incomplete outcome data } \\
\text { (attrition bias) } \\
\text { All outcomes }\end{array}$ & Low risk & $\begin{array}{l}\text { Data provided for all randomised individuals. We note that study authors re- } \\
\text { ported lung function results only for the per-protocol population, whereas } \\
\text { they reported all other outcomes for the intent-to-treat population. }\end{array}$ \\
\hline $\begin{array}{l}\text { Selective reporting (re- } \\
\text { porting bias) }\end{array}$ & High risk & $\begin{array}{l}\text { Study authors reported the primary outcome for the per-protocol data set on } \\
\text { the basis that this is a non-inferiority study. Furthermore, the primary outcome } \\
\text { considers lung function only over the first } 12 \text { weeks of treatment; a secondary } \\
\text { outcome assessed lung function in the full analysis set but considered only the } \\
\text { second } 12 \text { weeks of treatment. All in all, findings were quite confusing and in- } \\
\text { consistent. This trial was not reported as registered, and we cannot source a } \\
\text { protocol. }\end{array}$ \\
\hline
\end{tabular}

Other bias

High risk
The protocol suggests that only participants whose condition was well con- trolled within the last 2 weeks of the run-in period would go on to randomi- sation; however, it appears that a relatively high proportion of participants whose asthma was not controlled were included in the full analysis set. Results of this study are not well reported, and as the study does not appear to have been prospectively registered, and a protocol was not cited, it is difficult to as- certain whether selective outcome reporting occurred. Study sponsorship is not reported, although several authors worked for GSK. Key exclusion criteria of poor control according to ACQ were not defined or reported. A large propor- tion of poorly controlled randomised participants were not included in the pri- mary outcome analysis (but were included in the secondary outcome analy- sis). Reporting was confusing.


Total duration of study: 2-week run-in period; 12-week treatment period

'Run-in' period: 2-week run in period, during which participants remained on their existing doses of ICS ('high-dose' budesonide $400 \mu \mathrm{g}$ twice daily, beclomethasone $400 \mu \mathrm{g}$ twice daily or beclomethasone $500 \mu \mathrm{g}$ twice daily via a pMDI with a spacer; or 'low-dose' budesonide or beclomethasone $200 \mu \mathrm{g}$ twice daily)

Number of study centres and locations: UK

Study setting: primary care

Withdrawals: $147 / 631(23 \%)$ randomised participants withdrew during the treatment period

Date of study: not stated

N: 631 patients were randomised after a 2-week run-in period.

Mean age (range), years: budesonide OD: 44.1 (16.5-80.2); budesonide BID: 45.7 (16.7-77.0); no ICS dose change: 40.9 (16.2-80.2)

Gender M/F, n: budesonide OD: 100/128; budesonide BID: 90/101; no ICS dose change: 100/112

Severity of condition: baseline mean morning PEFR (SD), L/min: controlled on step 2. Budesonide OD: 437.2 (106.5); budesonide BID: 447.4 (111.3); no ICS dose change: 445.8 (100.9)

Diagnostic criteria: mild, well controlled

Baseline lung function - mean morning PEFR (SD), L/min: budesonide OD: 437.2 (106.5); budesonide BID: 447.4 (111.3); no ICS dose change: 445.8 (100.9)

\section{Smoking history: not stated}

Inclusion criteria: aged $\geq 16$ years; documented diagnosis of asthma (currently stable); asthma considered by physician to be well controlled (as per BTS guidelines); receiving $200 \mu \mathrm{g}$ twice daily (low dose) or 400/500 $\mu \mathrm{g}$ twice daily (high dose) budesonide or beclomethasone (via a pMDI \pm spacer) for 6 months before entry; patients on the higher dose of steroid were required to have used a large volume spacer for a minimum of 4 weeks before entry

Exclusion criteria: pregnant, at risk of pregnancy, breast feeding, brittle asthma, night shift workers. Within 3 months: any increase in total daily inhaled steroid dose; exacerbation resulting in hospitalisation or requiring nebulisation, oral/injectable/rectal steroids, beta blockers, sodium cromoglycate, sodium nedocromil, any unlicensed medication or fluticasone propionate. Within 1 week before the study: Patients were not permitted to have taken theophylline (or derivatives), any long-acting bronchodilators, ipratropium/oxitropium bromide or ketotifen.

Details of criteria for stepping-down treatment: Participants were eligible for randomisation if their diary cards showed that they had no nocturnal wakening due to asthma in the previous 7 nights, and if they fulfilled 3 of the following criteria:

asthma symptoms of no more than mild severity experienced on 3 or fewer days of the previous 7 days; using $\leq 1$ puff per day of inhaled bronchodilator on a maximum of 5 of the last 7 days; circadian variation in PEFR $<20 \%$ in the previous 7 days; morning PEFR $\geq 80 \%$ or predicted or best (if this value was greater than predicted) on 5 of the 7 previous days

Interventions

Intervention: Participants on an initial high dose of ICS (budesonide $400 \mu \mathrm{g}$ twice daily or beclomethasone $400 \mu \mathrm{g}$ twice daily or beclomethasone $500 \mu \mathrm{g}$ twice daily delivered via a pMDI and a spacer device) were randomised to receive budesonide $200 \mu \mathrm{g}$ twice daily via a turbuhaler or $400 \mu \mathrm{g}$ once daily (i.e. both groups represent a halving of the initial ICS dose). Participants on an initial low dose of ICS (budesonide or beclomethasone $200 \mu \mathrm{g}$ twice daily) were randomised to receive budesonide $100 \mu \mathrm{g}$ twice daily via a turbuhaler or $200 \mu \mathrm{g}$ once daily (i.e. both groups represent a halving of the initial ICS dose). 
Comparison: No change in initial dose of budesonide or beclomethasone.

Concomitant medications: Each patient was given terbutaline (Bricanyl) turbuhaler $500 \mu \mathrm{g}$ prn for rescue mediation during the run-in and throughout the study.

Excluded medications: See exclusion criteria.

Outcomes
Primary outcomes: morning PEFR recorded by diary cards (recorded at baseline, and at 4, 8 and 12 weeks)

Secondary outcomes: evening PEFR, proportion of symptom-free days/nights, proportion of beta 2 -agonist-free days/nights, sleep disturbance (all recorded via diary cards) quality of life (Juniper Asthma Quality of Life Questionnaire (Juniper 1993); PEFR measured at clinic visits; asthma severity measured at clinic visits; asthma control)

\section{Notes}

Funding for trial: not stated; likely Astra Pharmaceuticals

Notable conflicts of interest of trial authors: not stated. One study author was an employee of Astra Pharmaceuticals.

\section{Risk of bias}

\begin{tabular}{|c|c|c|}
\hline Bias & Authors' judgement & Support for judgement \\
\hline $\begin{array}{l}\text { Random sequence genera- } \\
\text { tion (selection bias) }\end{array}$ & Unclear risk & Insufficient information provided \\
\hline $\begin{array}{l}\text { Allocation concealment } \\
\text { (selection bias) }\end{array}$ & Unclear risk & Insufficient information provided \\
\hline $\begin{array}{l}\text { Blinding of participants } \\
\text { and personnel (perfor- } \\
\text { mance bias) } \\
\text { All outcomes }\end{array}$ & High risk & The study was open label. \\
\hline $\begin{array}{l}\text { Blinding of outcome as- } \\
\text { sessment (detection bias) } \\
\text { All outcomes }\end{array}$ & High risk & $\begin{array}{l}\text { The study was open label, and it does not appear that outcome assessors were } \\
\text { blinded to treatment. }\end{array}$ \\
\hline $\begin{array}{l}\text { Incomplete outcome data } \\
\text { (attrition bias) } \\
\text { All outcomes }\end{array}$ & Low risk & $\begin{array}{l}\text { Incomplete primary outcome data were reported, but the number of partici- } \\
\text { pants for whom data were missing was similar across OD/BD/pMDI groups. }\end{array}$ \\
\hline $\begin{array}{l}\text { Selective reporting (re- } \\
\text { porting bias) }\end{array}$ & High risk & $\begin{array}{l}\text { No study protocol available. The data for high-dose and low-dose groups were } \\
\text { pooled and were not presented individually. Study authors stated that sepa- } \\
\text { rate data were not presented individually because no significant differences } \\
\text { between the } 2 \text { dose groups were found for any of the analyses performed. }\end{array}$ \\
\hline Other bias & Unclear risk & $\begin{array}{l}\text { Unclear risk of bias: This is a complicated study, and some changes in inhaler } \\
\text { device appear to have occurred at the same time as changes in dose. Partic- } \\
\text { ipants entered the run-in period on their existing dose of ICS ('high' or 'low') } \\
\text { and were later randomised to remain on their existing dose, or step down to } \\
\text { half the dose in } 1 \text { of } 2 \text { different formats (half the dose twice daily, or the same } \\
\text { dose but only once daily). No data were reported for the run-in period. } \\
\text { Unclear risk of bias: Funding for the study is not reported. The paper has in- } \\
\text { dustry authors, and the company manufactures products that seem to match } \\
\text { the products reported upon. Funding for the study is not declared, but one } \\
\text { study author is employed by Astra. }\end{array}$ \\
\hline
\end{tabular}


Total duration of study: 1 year

'Run-in' period: 1 month

Number of study centres and locations: general practices in Western and Central Scotland

Study setting: primary care (general practice)

Withdrawals: 24/130 participants in the stepdown group and 22/129 in the control group discontinued the intervention. Analyses were performed on all randomised participants.

Date of study: The study was performed between May 1999 and October 2001.

\section{Participants}

N: 259 participants were randomised.

Mean age (SD), years: step-down 52.8, (14.5); control 55 (15.2)

Age range: $18-86$ years

Gender (M/F), n: step-down, 54/76; control, 54/75

Severity of condition: controlled on high-dose ICS (at least $1000 \mu \mathrm{g}$ BDP) plus possibly other drugs (steps 2-4)

Baseline lung function - \% predicted pre-salbutamol FEV $\mathbf{1}$ (SD), L/min: step-down, 80.3 (19.2); control, $80.1(18.6)$

Smoking history - current/former/never, n: step-down, 16/44/70; control, 17/49/63

Inclusion criteria: aged $\geq 18$ years; diagnosis of asthma $\geq 1$ year; treated with $\geq 800 \mu$ inhaled BDP (or budesonide or fluticasone propionate at equivalent dosage)

Exclusion criteria: required oral corticosteroids or attended general practice or hospital within 2 months; inability to use peak flow meter; treatment with immunosuppressive drugs; serious illness; alcohol, substance or drug misuse; pregnancy; participation in other research within the past 6 months

Details of criteria for stepping down treatment: stable asthma (i.e. good control) assessed at end of run-in period and at 3, 6, 9 and 12 months. Good control was defined as an asthma morbidity score $\leq 2$, no visits to general practice or hospital since previous visit and peak flow $\geq$ target flow on 8 of the previous 14 days; if peak flow data were missing, the first two criteria were used.

Concomitant medications: Reliever inhalers were permitted. $36.9 \%$ of the step-down group and $30.2 \%$ of the control group were receiving a concomitant LABA.

Excluded medications: immunosuppresive drugs (short asthma morbidity score (Rimmington 1997); scores ranged from 0 (perfect control) to 8 (very poor control))

Secondary outcomes: adverse events, health-related quality of life (EuroQoL and St George's Respiratory Questionnaire), annual corticosteroid dose 
Hawkins 2003 (Continued)

Notable conflicts of interest of trial authors: Study authors had received funding, and various phar-

maceutical companies including GlaxoSmithKline provided the study inhalers.

\section{Risk of bias}

\begin{tabular}{|c|c|c|}
\hline Bias & Authors' judgement & Support for judgement \\
\hline $\begin{array}{l}\text { Random sequence genera- } \\
\text { tion (selection bias) }\end{array}$ & Low risk & $\begin{array}{l}\text { Well-described randomisation with computer-generated randomisation strati- } \\
\text { fied by centre }\end{array}$ \\
\hline $\begin{array}{l}\text { Allocation concealment } \\
\text { (selection bias) }\end{array}$ & Low risk & $\begin{array}{l}\text { Computer-allocated randomisation sequence; randomisation code withheld } \\
\text { from investigators until study completion }\end{array}$ \\
\hline $\begin{array}{l}\text { Blinding of participants } \\
\text { and personnel (perfor- } \\
\text { mance bias) } \\
\text { All outcomes }\end{array}$ & Low risk & $\begin{array}{l}\text { Participants and personnel were blinded to treatment allocation via use of } \\
\text { identical inhaler packs. }\end{array}$ \\
\hline $\begin{array}{l}\text { Blinding of outcome as- } \\
\text { sessment (detection bias) } \\
\text { All outcomes }\end{array}$ & Low risk & Randomisation code was maintained blind until the end of the study. \\
\hline $\begin{array}{l}\text { Incomplete outcome data } \\
\text { (attrition bias) } \\
\text { All outcomes }\end{array}$ & Low risk & $\begin{array}{l}\text { Primary outcome data were reported for all participants as intention to treat. } \\
\text { Some data for health status secondary outcome measures were missing (not } \\
\text { explained), but the number of participants for whom data were missing was } \\
\text { similar in both treatment groups. Lung function was not reported during or at } \\
\text { the end of the treatment period. }\end{array}$ \\
\hline $\begin{array}{l}\text { Selective reporting (re- } \\
\text { porting bias) }\end{array}$ & High risk & $\begin{array}{l}\text { Protocol was not available. It is not clear why study authors did not present } \\
\text { lung function as, according to the Methods section, participants did monitor } \\
\text { lung function for } 2 \text { weeks before each visit. Detailed adverse event data were } \\
\text { not presented. }\end{array}$ \\
\hline Other bias & Low risk & $\begin{array}{l}\text { Study medication was provided by industry, but study was funded by NHS R\&D } \\
\text { programme on asthma development. No industry was involved in authorship } \\
\text { of the paper. }\end{array}$ \\
\hline
\end{tabular}

Juniper 1991

Methods

Study design: randomised controlled trial, double-blind, parallel group

Total duration of study: 3 months

'Run-in' period: no run-in (this is a follow-up extension to a previous study)

Number of study centres and locations: Firestone Regional Chest and Allergy Clinic at St Joseph's Hospital and the McMaster University Medical Centre in Hamilton, Canada

Study setting: secondary care (asthma clinic)

Withdrawals: All 28 participants completed the study

Date of study: not reported

Participants N: 28. A subgroup of 14 participants were relevant to this review.

Mean age: not reported. Mean age in parent study was 42 years (Juniper 1990).

Age range: not reported 


\section{Gender: not reported}

Severity of condition: controlled on step 2 (mild to moderate: approximately half of participants were 'steroid dependent')

Baseline lung function: Individual participant data were reported. At entry to initial study, all participants had airway hyper-responsiveness to methacholine ( $\mathrm{PC} 20<8.0 \mathrm{mg} / \mathrm{mL})$ and symptomatic asthma.

Smoking history: not reported

Inclusion criteria and exclusion criteria: successful completion of previous study

Details of criteria for step-down treatment: not reported

Comparison: no change in budesonide dose among steroid-dependent participants $(n=8)$

Concomitant medications: Bronchodilator medication was permitted (long-acting vs short-acting not specified).

Excluded medications: not reported

Outcomes

Primary outcomes: airway responsiveness to methacholine (measured with a standardised tidal breathing protocol); clinical asthma severity (i.e. asthma control assessed via asthma severity questionnaire). The questionnaire comprised 6 items: awakened at night by symptoms; awakened in the morning by symptoms; limitation of normal daily activities; sputum; use of bronchodilator more than 4 times per day; $\mathrm{FEV}_{1}$ prebronchodilator $<70 \%$ predicted (One point was scored for each of the first 5 items that had been positive on $\geq 1$ day during the previous week; 1 point was scored for reduced spirometry; therefore, the maximum asthma severity score (i.e. worst control) was 6).

Secondary outcomes: bronchodilator use; allergen exposure score; upper respiratory tract infection score

Notes $\quad$ Funding for trial: Funding was not reported.

Notable conflicts of interest of trial authors: Conflicts of interest were not reported.

\section{Risk of bias}

\begin{tabular}{lll}
\hline Bias & Authors' judgement & Support for judgement \\
\hline $\begin{array}{l}\text { Random sequence genera- } \\
\text { tion (selection bias) }\end{array}$ & Unclear risk & Insufficient information provided \\
\hline $\begin{array}{l}\text { Allocation concealment } \\
\text { (selection bias) }\end{array}$ & Unclear risk & Insufficient information provided \\
\hline $\begin{array}{l}\text { Blinding of participants } \\
\text { and personnel (perfor- } \\
\text { mance bias) }\end{array}$ & Low risk & The study was reported as double-blind. \\
All outcomes & & \\
\hline
\end{tabular}

Blinding of outcome as-
sessment (detection bias) $\quad$ Low risk The study was reported as double-blind.

All outcomes

Incomplete outcome data Low risk (attrition bias)

All outcomes
All 28 randomised participants completed the study, and it appears that data were reported for all 28 participants. 
Juniper 1991 (Continued)

Selective reporting (reporting bias)
High risk

Study authors state, "During analysis, it was found that all the outcomes in the two reduction groups were very similar, and also, the outcomes in the two groups in whom steroids were not reduced were very similar. Therefore, for simplicity, the data have been combined and are presented as two groups, reduced and maintained".

No protocol was available; no prespecified analysis plan was prepared. Group data were combined as described above.

Other bias Low risk None identified

Knox 2007

Methods

Study design: randomised controlled, double-blind, double-dummy, parallel group

Total duration of study: 14 weeks

'Run-in' period: 2 weeks

Number of study centres and locations: 16 centres (8 each in UK and Belgium)

Study setting: not stated

Withdrawals: 5 participants (CIC $160 \mu \mathrm{g}, \mathrm{n}=4$; FP $250 \mu \mathrm{g}, \mathrm{n}=1$ )

Date of study: October 2004 to July 2005

N: 111 randomised

Mean age, years: CIC $160 \mu \mathrm{g}$ OD: 43; FP $250 \mu \mathrm{g}$ BID: 46

Age range, years: $18-75$

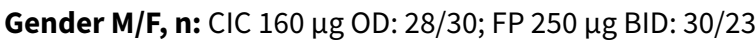

Severity of condition: controlled on step 2

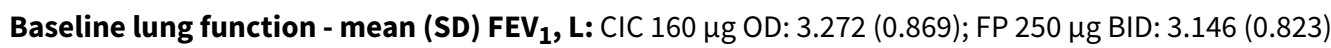

Smoking history - non-smoker/ex-smoker/current smoker, n: CIC $160 \mu \mathrm{g}$ OD: 38/18/2; FP $250 \mu \mathrm{g}$ BID: $34 / 18 / 1$

Inclusion criteria: male and female patients aged 17-75 years; diagnosis of asthma as defined by American Thoracic Society guidelines for at least 6 months, but otherwise in good health; $\mathrm{FEV}_{1} \geq 90 \%$ of predicted; maintained asthma control over previous 3 months using fluticasone propionate $250 \mu \mathrm{g}$ twice daily, or equivalent, with short-acting bronchodilator use as rescue medication only

Exclusion criteria: concomitant severe disease, such as a lower respiratory tract infection; chronic obstructive pulmonary disease or other relevant lung diseases; more than 1 emergency care visit or hospitalisation due to asthma exacerbations in the previous year; or clinically relevant abnormal laboratory values suggesting an unknown disease. Other exclusion criteria were use of systemic glucocorticoids, long-acting $\beta_{2}$-agonists, oral $\beta_{2}$-agonists and sustained-release xanthines within 3 months before study entry; pregnancy and breast-feeding among female patients; and ex-smokers or current smokers with $\geq 10$ pack-years.

Details of criteria for step-down treatment: Participants were randomised to step-down (for eligibility, see inclusion and exclusion criteria). 
Knox 2007 (Continued)

Interventions

Intervention: ciclesonide $160 \mu \mathrm{g}$ OD (i.e. 50\% reduction according to GINA 2016)

Comparison: fluticasone propionate $250 \mu \mathrm{g}$ BID (i.e. no change)

Concomitant medications: short-acting bronchodilator used as rescue medication only

Excluded medications: See exclusion criteria.

\section{Outcomes}

Primary outcomes: efficacy - percentage of days with asthma control (defined as days without asthma symptoms and without rescue medication use); asthma symptom-free days; rescue medication-free days; and nocturnal awakening-free days. Safety - adverse events

Secondary outcomes: efficacy - $\mathrm{FEV}_{1}$; forced vital capacity (FVC); PEF from spirometry; PEF from participant diaries measured on a Mini-Wright PEF meter; asthma symptom scores from participant diaries (sum scores based on a 9-point scale, with 0 indicating no symptoms); use of rescue medication; number of participants with an asthma exacerbation; and time to onset of the first asthma exacerbation. Safety - vital signs (blood pressure and pulse rate); standard laboratory tests (including haematology, blood chemistry and urinalysis); and number of participants with oral candidiasis

Notes Funding for trial: This study was funded and sponsored by ALTANA Pharma AG, a member of the Nycomed Group.

Notable conflicts of interest of trial authors: Editorial assistance for preparation of the manuscript was provided by Nathan Price-Lloyd, PhD, Medicus International, which was funded by ALTANA Pharma AG, a member of the Nycomed Group. Study authors reported no conflicts of interest.

\section{Risk of bias}

\begin{tabular}{|c|c|c|}
\hline Bias & Authors' judgement & Support for judgement \\
\hline $\begin{array}{l}\text { Random sequence genera- } \\
\text { tion (selection bias) }\end{array}$ & Unclear risk & Insufficient information provided \\
\hline $\begin{array}{l}\text { Allocation concealment } \\
\text { (selection bias) }\end{array}$ & Unclear risk & Insufficient information provided \\
\hline $\begin{array}{l}\text { Blinding of participants } \\
\text { and personnel (perfor- } \\
\text { mance bias) } \\
\text { All outcomes }\end{array}$ & Low risk & The study was reported as double-blind, double-dummy. \\
\hline $\begin{array}{l}\text { Blinding of outcome as- } \\
\text { sessment (detection bias) } \\
\text { All outcomes }\end{array}$ & Low risk & The study was reported as double-blind, double-dummy. \\
\hline $\begin{array}{l}\text { Incomplete outcome data } \\
\text { (attrition bias) } \\
\text { All outcomes }\end{array}$ & Low risk & $\begin{array}{l}\text { Intention-to-treat analyses were performed for safety analyses and comprised } \\
\text { all randomised participants. Some data for lung function analyses were miss- } \\
\text { ing, but only from } 3 \text { participants in the step-down group. }\end{array}$ \\
\hline $\begin{array}{l}\text { Selective reporting (re- } \\
\text { porting bias) }\end{array}$ & Unclear risk & $\begin{array}{l}\text { Protocol was not available; however, the range of outcomes seems fairly com- } \\
\text { prehensive. }\end{array}$ \\
\hline Other bias & Low risk & None identified \\
\hline
\end{tabular}

\section{Magnussen 2000}

Methods Study design: randomised controlled, double-blind, double-dummy, parallel group


Magnussen 2000 (Continued)

Total duration of study: 14 weeks

'Run-in' period: 4 weeks

Number of study centres and locations: 18 pulmonology practices

Study setting: pulmonology outpatient practices

Withdrawals: none reported

Date of study: November 1996 to October 1997
Participants

\section{N: 150}

Mean (SD) age, years: $400 \mu \mathrm{g} /$ day BDP: 43 (15); $1000 \mu \mathrm{g} /$ day BDP: 42 (15)

Age range: not reported

Gender - M/F, n: $400 \mu \mathrm{g} /$ day BDP: 22/50; $1000 \mu \mathrm{g} /$ day BDP: 30/48

Severity of condition: step 2

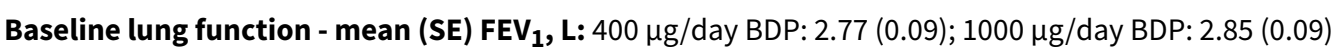

Smoking history: not reported

Inclusion criteria and exclusion criteria, allowable range: age 18-75 years; use of inhaled steroids for $\geq 3$ months (BDP $1000 \mathrm{mg}$ or BUD 800-1000 mg); use of $\beta_{2}$-agonists on demand ( $\geq 1$ puffs/d); reversible airflow obstruction assessed within the last 2 years; change in $\mathrm{FEV} \geq 12 \%$; change in $\mathrm{PEF} \geq 20 \%$; bronchial hyper-responsiveness to inhaled histamine (PC20 FEV $1 \geq 4 \mathrm{mg} / \mathrm{mL}$ ); baseline $\mathrm{FEV}_{1} \geq 60 \%$ of predicted; variability of baseline $\mathrm{FEV}_{1}$ during run-in period $\leq 15 \%$

Details of criteria for step-down treatment: Participants were randomised to step-down (for eligibility, see inclusion and exclusion criteria).
Intervention: hydrofluoroalkane beclomethasone $400 \mu \mathrm{g} /$ day (i.e. $<50 \%$ dose reduction)

Comparison: chlorofluorocarbon beclomethasone $1000 \mu \mathrm{g} /$ day.

Concomitant medications: not reported; likely that use of short-acting bronchodilators as rescue medication was permitted

Excluded medications: none specified
Primary outcomes: Efficacy - morning peak flow; Safety - adverse events

Secondary outcomes: evening peak flow, $\mathrm{FEV}_{1}$, concentration of inhaled histamine causing a $20 \%$ decline in $\mathrm{FEV}_{1}$, frequency of $\beta_{2}$-agonist use, daily asthma symptom score (0 represents no symptoms; 5 represents severe symptoms); and sleep disturbance score. Safety - oropharyngeal candidiasis; reported hoarseness; clinical laboratory tests (i.e. haematology, serum chemistry, urine analysis); and vital signs (i.e. sitting pulse rate, blood pressure, ECG)

Funding for trial: 3M Medica (Borken, Germany)

Notable conflicts of interest of trial authors: not reported; however, several study authors were employees of 3M Medica

\section{Risk of bias}

Bias Authors' judgement Support for judgement


Magnussen 2000 (Continued)

Random sequence genera- Unclear risk $\quad$ Insufficient information provided
tion (selection bias)

Allocation concealment Unclear risk Insufficient information provided
(selection bias)

(selection bias)

Blinding of participants Low risk The study was reported as double-blind.
and personnel (perfor-
mance bias)
All outcomes

Blinding of outcome as- Low risk The study was reported as double-blind.
sessment (detection bias)

All outcomes

\begin{tabular}{|c|c|c|}
\hline $\begin{array}{l}\text { Incomplete outcome data } \\
\text { (attrition bias) }\end{array}$ & Low risk & $\begin{array}{l}\text { Outcome data appear complete. Data appear to be reported for all ran- } \\
\text { domised participants. }\end{array}$ \\
\hline
\end{tabular}

\begin{tabular}{lll}
\hline $\begin{array}{l}\text { Selective reporting (re- } \\
\text { porting bias) }\end{array}$ & High risk & $\begin{array}{l}\text { Protocol was not available. Reporting of safety results appears to be fairly se- } \\
\text { lective (SAEs not reported, details of individual AEs not reported). }\end{array}$ \\
\hline Other bias & Low risk & None identified \\
\hline
\end{tabular}

Abbreviations: BDP, beclomethasone dipropionate; BID, twice daily; BTS, British Thoracic Society; CFC, chlorofluorocarbon; CIC, ciclesonide; ECG, electrocardiogram; FEV $_{1}$, forced expiratory volume in 1 second; FP, fluticasone propionate; FVC, forced vital capacity; GOAL, Gaining Optimal Asthma Control study; ICS, inhaled corticosteroid; LABA, long-acting beta agonist; NHS, National Health Service; $\mathrm{OD}$, once daily; PC20, provocative concentration that produces a $20 \%$ reduction in $\mathrm{FEV}_{1}$ from baseline value; PEF, peak expiratory flow; PEFR, peak expiratory flow rate; $\mathrm{pMDI}$, pressurised metered-dose inhaler; QoL, quality of life; R\&D, research and development; SD, standard deviation; SE, standard error; SFC, salmeterol formoterol combination; UK, United Kingdom.

Characteristics of excluded studies [ordered by study ID]

\begin{tabular}{ll}
\hline Study & Reason for exclusion \\
\hline Aalbers 2004 & Wrong intervention \\
\hline Adachi 2001 & Wrong patient population \\
\hline ALA 2007 & Wrong intervention \\
\hline Anonymous 1979 & Wrong intervention \\
\hline Baba 1999 & Wrong study design \\
\hline Baba 2000 & Wrong intervention \\
\hline Bateman 2005 & Wrong comparator \\
\hline Belda 2006 & Wrong study design \\
\hline Boulet 1990 & Wrong route of administration \\
\hline Brambilla 1994 & Wrong comparator \\
\hline
\end{tabular}




\begin{tabular}{|c|c|}
\hline Study & Reason for exclusion \\
\hline Britton 1997 & Wrong study design \\
\hline Bruggenjurgen 2005 & Wrong intervention \\
\hline Busse 2003 & Wrong study design \\
\hline Campbell 1998 & Wrong intervention \\
\hline Casale 2003 & Wrong intervention \\
\hline Chanez 2001 & Wrong intervention \\
\hline Chiu 2011 & Wrong intervention \\
\hline Chung 2002 & Wrong intervention \\
\hline Davies 1977 & Wrong intervention \\
\hline Dorinsky 2003 & Wrong intervention \\
\hline Fardon 2005 & Wrong intervention \\
\hline Fardon 2007 & Wrong intervention \\
\hline FitzGerald 2003 & Wrong intervention \\
\hline FitzGerald 2005 & Wrong intervention \\
\hline FLIQ96 2005 & Wrong study design \\
\hline Fowler 2002 & Wrong intervention \\
\hline Haggart 2004 & Wrong intervention \\
\hline Hamada 2008 & Wrong study design \\
\hline Kardos 2001 & Wrong intervention \\
\hline Kawagishi 2000 & Wrong study design \\
\hline Keonig 2004 & Wrong intervention \\
\hline Massanari 2008 & Wrong intervention \\
\hline McKinlay 2011 & Wrong intervention \\
\hline Mikloweit 2000 & Wrong study design \\
\hline Obase 2013 & Wrong intervention \\
\hline Paggiaro 2011 & Wrong comparator \\
\hline Reddel 2007 & Wrong intervention \\
\hline Rumbak 1998 & Wrong intervention \\
\hline
\end{tabular}




\begin{tabular}{ll}
\hline Study & Reason for exclusion \\
\hline Schmier 2003 & Wrong route of administration \\
\hline Shamsul 2007 & Wrong intervention \\
\hline Ställberg 2003 & Wrong intervention \\
\hline
\end{tabular}

\section{DATA AND ANALYSES}

Comparison 1. ICS dose reduction versus no change in ICS dose (no concomitant LABA)

\begin{tabular}{|c|c|c|c|c|}
\hline Outcome or subgroup title & No. of studies & $\begin{array}{l}\text { No. of partici- } \\
\text { pants }\end{array}$ & Statistical method & Effect size \\
\hline 1 Exacerbation requiring OCS & 2 & 261 & Odds Ratio (M-H, Random, 95\% Cl) & $1.86[0.16,21.09]$ \\
\hline 2 Asthma control & 1 & & $\begin{array}{l}\text { Mean Difference (IV, Random, 95\% } \\
\mathrm{Cl} \text { ) }\end{array}$ & Totals not selected \\
\hline 3 All-cause SAEs & 2 & 742 & Odds Ratio (M-H, Random, 95\% Cl) & $1.24[0.25,6.25]$ \\
\hline 4 Steroid-related AEs & 2 & 261 & Odds Ratio (M-H, Random, 95\% Cl) & $0.76[0.16,3.54]$ \\
\hline $\begin{array}{l}5 \text { Juniper AQLQ score } \\
\text { (change from baseline) }\end{array}$ & 1 & & $\begin{array}{l}\text { Mean Difference (IV, Random, 95\% } \\
\mathrm{Cl} \text { ) }\end{array}$ & Totals not selected \\
\hline $\begin{array}{l}6 \text { Lung function, PEFR morn- } \\
\text { ing (L/min) }\end{array}$ & 3 & 875 & $\begin{array}{l}\text { Mean Difference (IV, Random, 95\% } \\
\mathrm{Cl} \text { ) }\end{array}$ & $-5.98[-19.47,7.51]$ \\
\hline 7 Lung function, $\mathrm{FEV}_{1}(\mathrm{~L})$ & 2 & 261 & $\begin{array}{l}\text { Mean Difference (IV, Random, 95\% } \\
\mathrm{Cl} \text { ) }\end{array}$ & $-0.02[-0.12,0.08]$ \\
\hline
\end{tabular}

Analysis 1.1. Comparison 1 ICS dose reduction versus no change in ICS dose (no concomitant LABA), Outcome 1 Exacerbation requiring $O C S$.

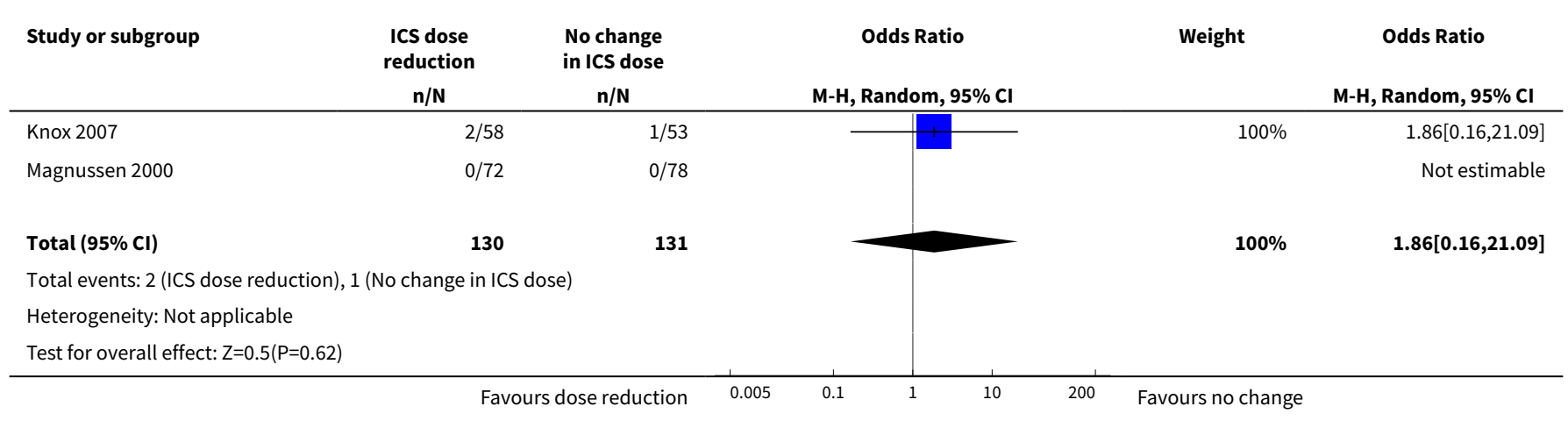


Analysis 1.2. Comparison 1 ICS dose reduction versus no change in ICS dose (no concomitant LABA), Outcome 2 Asthma control.

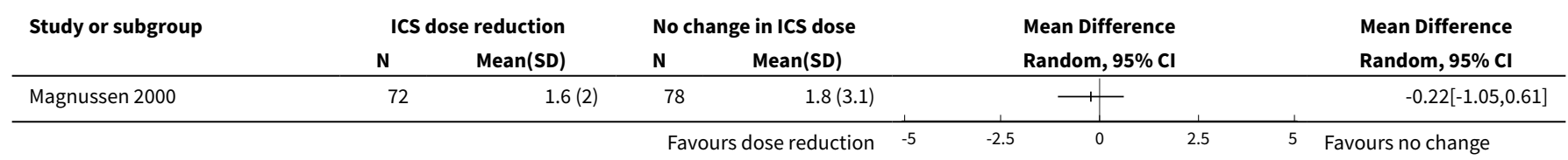

Analysis 1.3. Comparison 1 ICS dose reduction versus no change in ICS dose (no concomitant LABA), Outcome 3 All-cause SAEs.

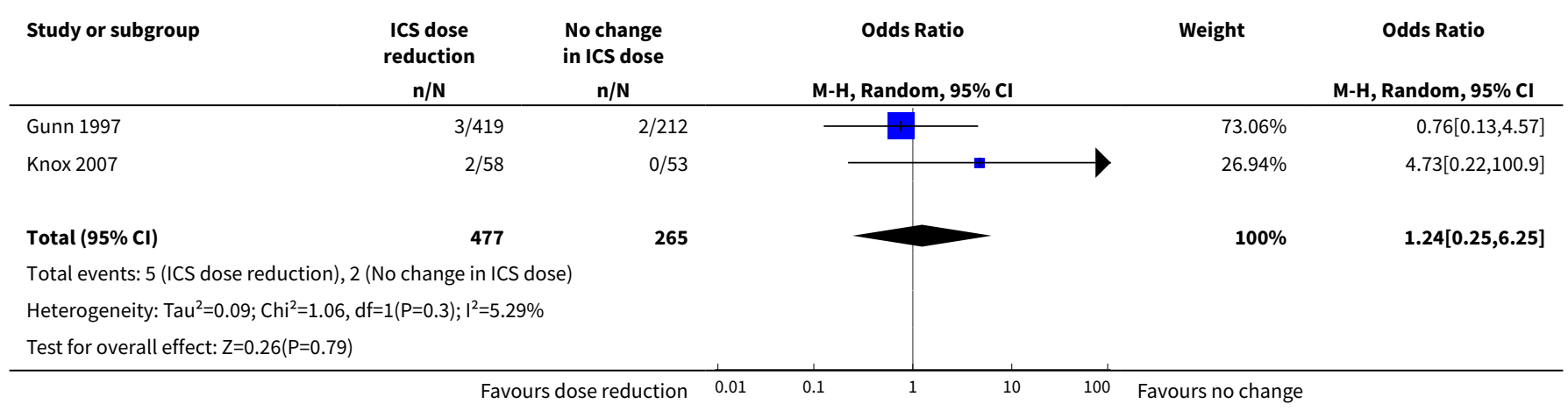

Analysis 1.4. Comparison 1 ICS dose reduction versus no change in ICS dose (no concomitant LABA), Outcome 4 Steroid-related AEs.

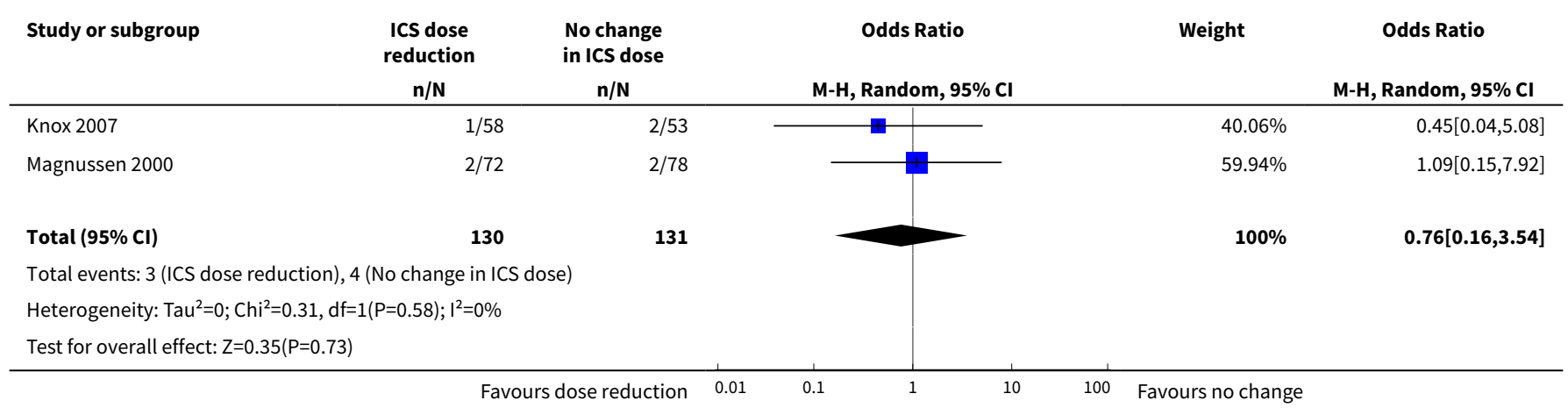

Analysis 1.5. Comparison 1 ICS dose reduction versus no change in ICS dose (no concomitant LABA), Outcome 5 Juniper AQLQ score (change from baseline).

\begin{tabular}{|c|c|c|c|c|c|c|c|}
\hline \multirow[t]{2}{*}{ Study or subgroup } & \multicolumn{2}{|c|}{ ICS dose reduction } & \multicolumn{2}{|c|}{ No change in ICS dose } & \multirow{2}{*}{\multicolumn{2}{|c|}{$\begin{array}{l}\text { Mean Difference } \\
\text { Random, 95\% Cl }\end{array}$}} & \multirow{2}{*}{$\begin{array}{l}\text { Mean Difference } \\
\text { Random, } 95 \% \mathrm{Cl}\end{array}$} \\
\hline & $\mathbf{N}$ & $\operatorname{Mean}(S D)$ & $\mathbf{N}$ & $\operatorname{Mean}(\mathrm{SD})$ & & & \\
\hline Gunn 1997 & 369 & $-0.2(0.8)$ & 185 & $0(0.6)$ & $千$ & & $-0.21[-0.33,-0.09]$ \\
\hline
\end{tabular}


Analysis 1.6. Comparison 1 ICS dose reduction versus no change in ICS dose (no concomitant LABA), Outcome 6 Lung function, PEFR morning (L/min).

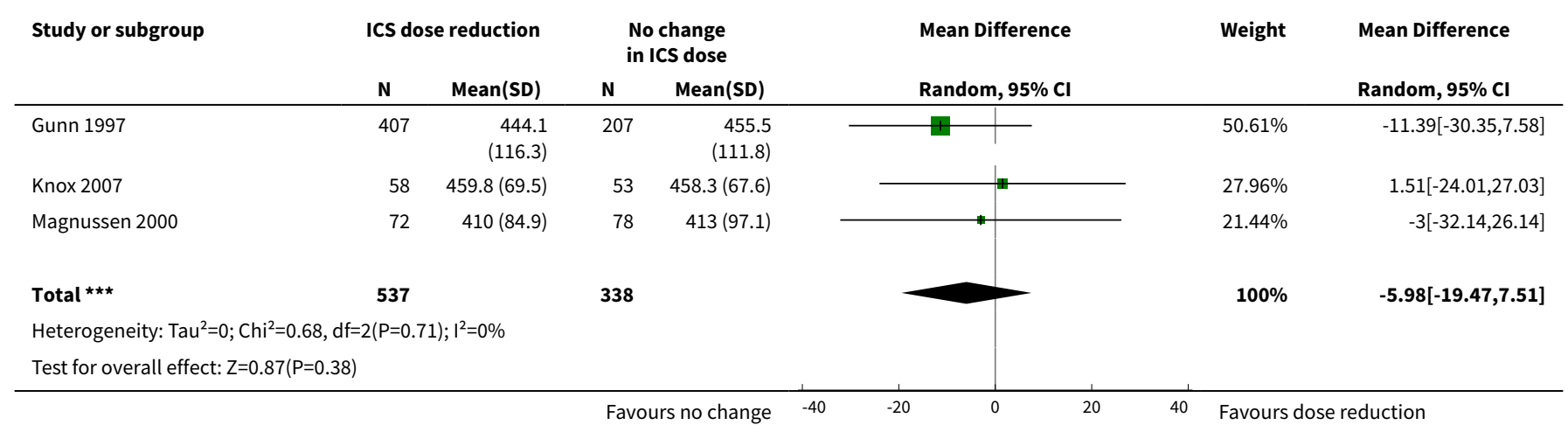

Analysis 1.7. Comparison 1 ICS dose reduction versus no change in ICS dose (no concomitant LABA), Outcome 7 Lung function, FEV $_{1}$ (L).

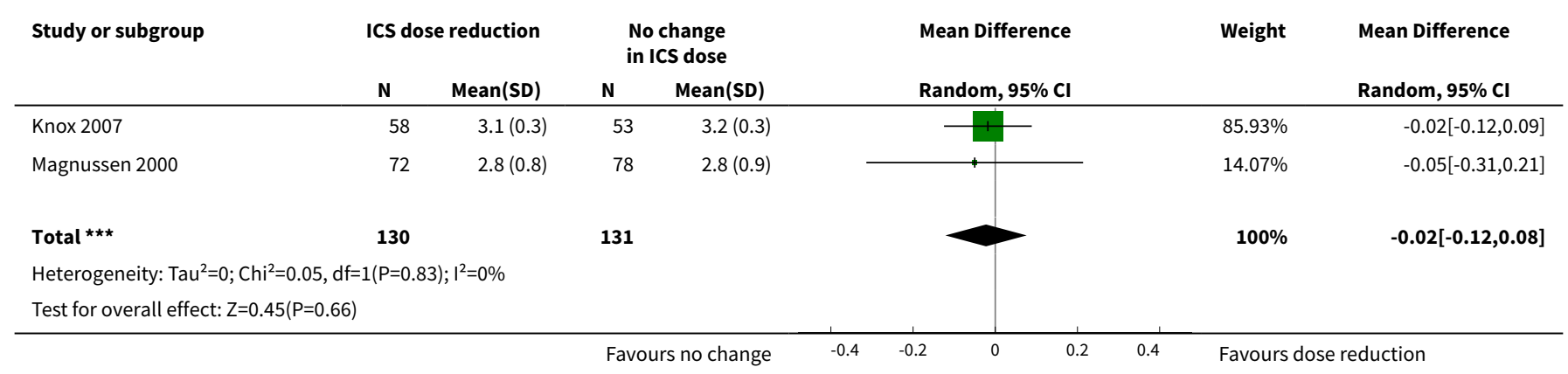

\section{Comparison 2. ICS dose reduction versus no change in ICS dose (concomitant LABA)}

\begin{tabular}{|c|c|c|c|c|}
\hline Outcome or subgroup title & No. of studies & $\begin{array}{l}\text { No. of partici- } \\
\text { pants }\end{array}$ & Statistical method & Effect size \\
\hline 1 Exacerbation requiring OCS & 2 & 569 & $\begin{array}{l}\text { Odds Ratio (M-H, Random, } \\
95 \% \mathrm{Cl})\end{array}$ & $1.31[0.82,2.08]$ \\
\hline $\begin{array}{l}2 \text { Asthma control (short asthma mor- } \\
\text { bidity score), change from baseline }\end{array}$ & 1 & & $\begin{array}{l}\text { Mean Difference (IV, Random, } \\
95 \% \mathrm{CI})\end{array}$ & $\begin{array}{l}\text { Totals not select- } \\
\text { ed }\end{array}$ \\
\hline $\begin{array}{l}3 \text { Asthma control (Asthma Severity } \\
\text { Questionnaire) }\end{array}$ & 1 & & $\begin{array}{l}\text { Mean Difference (IV, Random, } \\
95 \% \mathrm{CI} \text { ) }\end{array}$ & $\begin{array}{l}\text { Totals not select- } \\
\text { ed }\end{array}$ \\
\hline 4 All-cause SAEs & 2 & 569 & $\begin{array}{l}\text { Odds Ratio (M-H, Random, } \\
95 \% \mathrm{Cl})\end{array}$ & $0.60[0.11,3.33]$ \\
\hline $\begin{array}{l}5 \text { EuroQoL score (change from base- } \\
\text { line) }\end{array}$ & 1 & & $\begin{array}{l}\text { Mean Difference (IV, Random, } \\
95 \% \mathrm{CI})\end{array}$ & $\begin{array}{l}\text { Totals not select- } \\
\text { ed }\end{array}$ \\
\hline $\begin{array}{l}6 \text { St. George's Respiratory Scale score } \\
\text { (change from baseline) }\end{array}$ & 1 & & $\begin{array}{l}\text { Mean Difference (IV, Random, } \\
95 \% \mathrm{CI})\end{array}$ & $\begin{array}{l}\text { Totals not select- } \\
\text { ed }\end{array}$ \\
\hline
\end{tabular}




\begin{tabular}{|c|c|c|c|c|}
\hline Outcome or subgroup title & No. of studies & $\begin{array}{l}\text { No. of partici- } \\
\text { pants }\end{array}$ & Statistical method & Effect size \\
\hline $\begin{array}{l}7 \text { Lung function, PEFR morning (L/ } \\
\text { min) (change from baseline) }\end{array}$ & 1 & & $\begin{array}{l}\text { Mean Difference (IV, Random, } \\
95 \% \mathrm{CI} \text { ) }\end{array}$ & $\begin{array}{l}\text { Totals not select- } \\
\text { ed }\end{array}$ \\
\hline $\begin{array}{l}8 \text { Lung function, reduction in } \mathrm{FEV}_{1}(\% \\
\text { predicted, change from baseline) }\end{array}$ & 1 & & $\begin{array}{l}\text { Mean Difference (IV, Random, } \\
95 \% \mathrm{CI})\end{array}$ & $\begin{array}{l}\text { Totals not select- } \\
\text { ed }\end{array}$ \\
\hline $\begin{array}{l}9 \text { Exacerbation requiring hospitalisa- } \\
\text { tion }\end{array}$ & 2 & 569 & $\begin{array}{l}\text { Odds Ratio (M-H, Random, } \\
95 \% \mathrm{Cl})\end{array}$ & $4.06[0.45,36.86]$ \\
\hline 10 Exacerbation requiring ED visit & 1 & & $\begin{array}{l}\text { Odds Ratio (M-H, Random, } \\
95 \% \mathrm{Cl})\end{array}$ & $\begin{array}{l}\text { Totals not select- } \\
\text { ed }\end{array}$ \\
\hline 11 Mortality & 1 & 310 & $\begin{array}{l}\text { Odds Ratio (M-H, Random, } \\
95 \% \mathrm{Cl})\end{array}$ & $0.0[0.0,0.0]$ \\
\hline
\end{tabular}

Analysis 2.1. Comparison 2 ICS dose reduction versus no change in ICS dose (concomitant LABA), Outcome 1 Exacerbation requiring OCS.

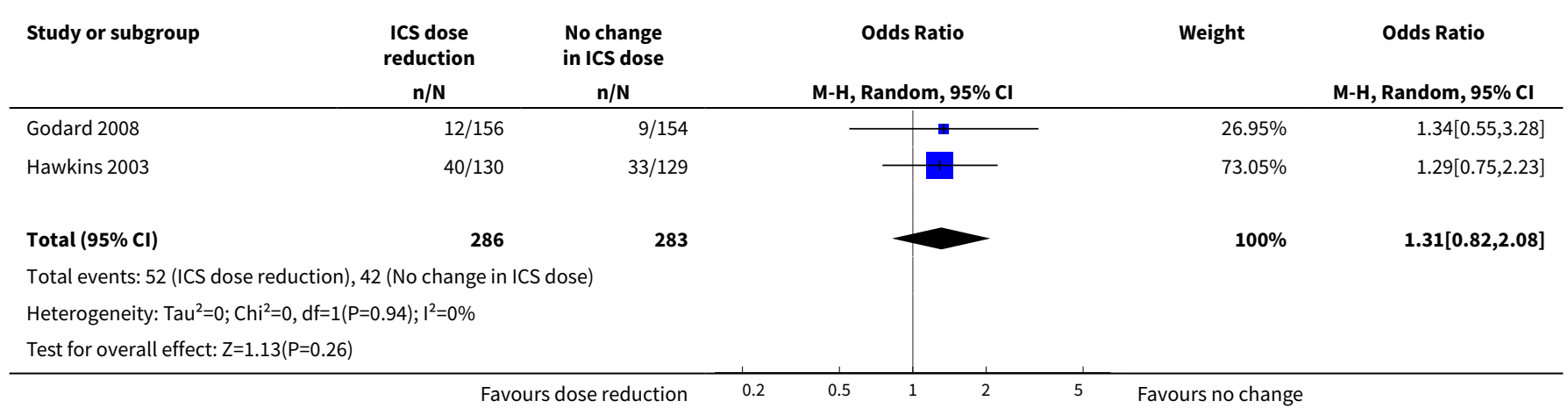

Analysis 2.2. Comparison 2 ICS dose reduction versus no change in ICS dose (concomitant LABA), Outcome 2 Asthma control (short asthma morbidity score), change from baseline.

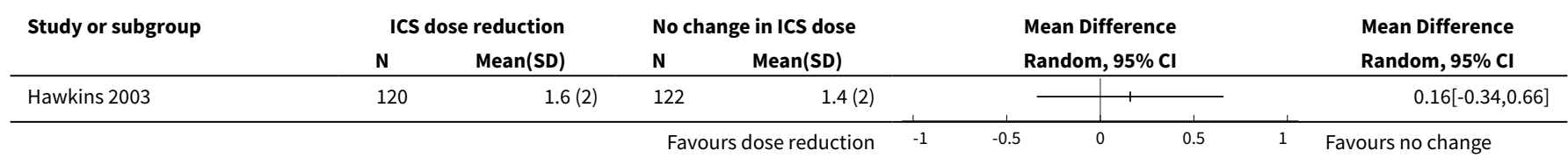

Analysis 2.3. Comparison 2 ICS dose reduction versus no change in ICS dose (concomitant LABA), Outcome 3 Asthma control (Asthma Severity Questionnaire).

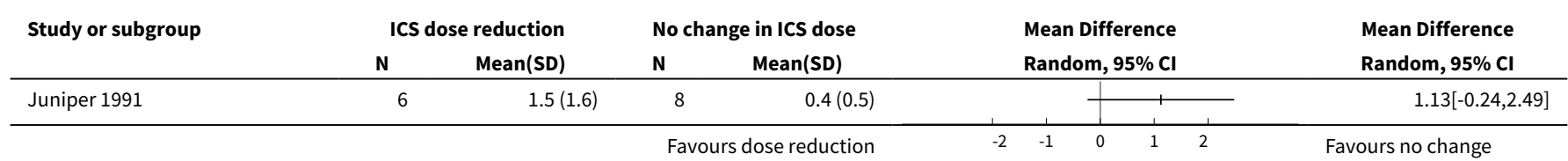


Analysis 2.4. Comparison 2 ICS dose reduction versus no change in ICS dose (concomitant LABA), Outcome 4 All-cause SAEs.

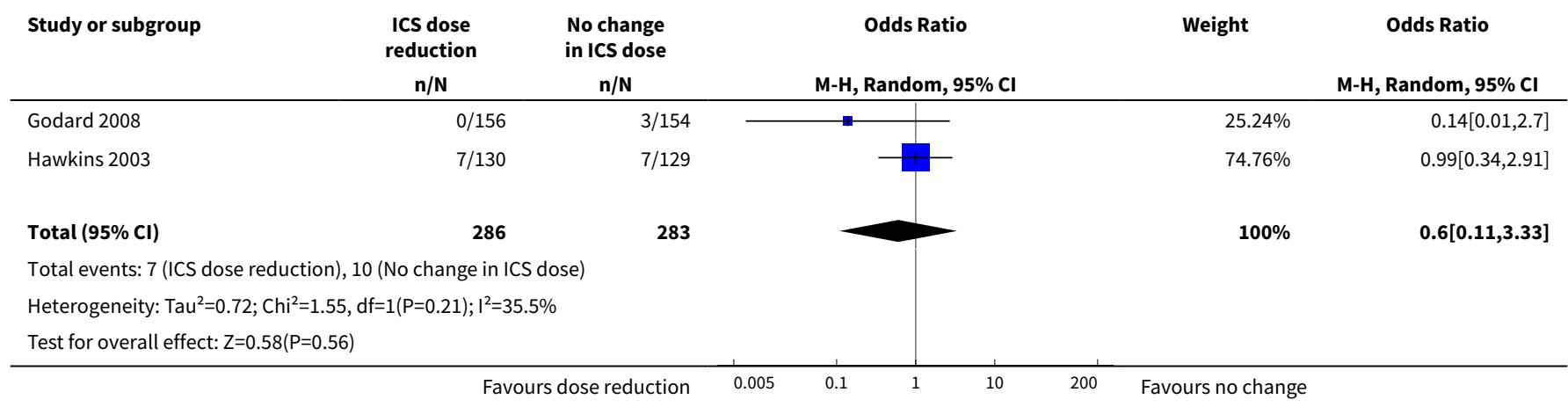

Analysis 2.5. Comparison 2 ICS dose reduction versus no change in ICS dose (concomitant LABA), Outcome 5 EuroQoL score (change from baseline).

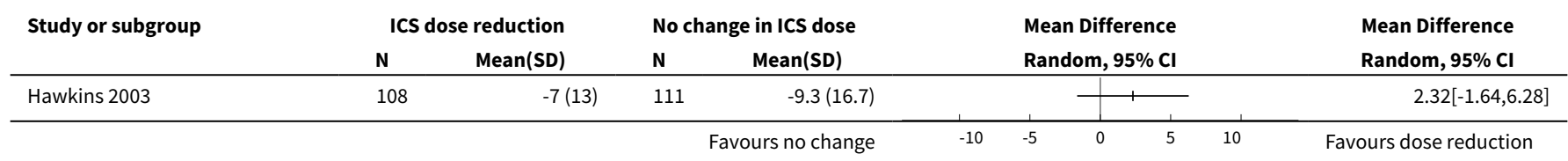

Analysis 2.6. Comparison 2 ICS dose reduction versus no change in ICS dose (concomitant LABA), Outcome 6 St. George's Respiratory Scale score (change from baseline).

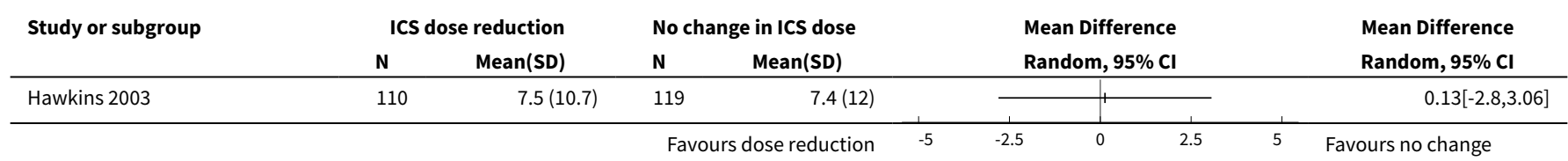

Analysis 2.7. Comparison 2 ICS dose reduction versus no change in ICS dose (concomitant LABA), Outcome 7 Lung function, PEFR morning ( $\mathrm{L} / \mathrm{min}$ ) (change from baseline).

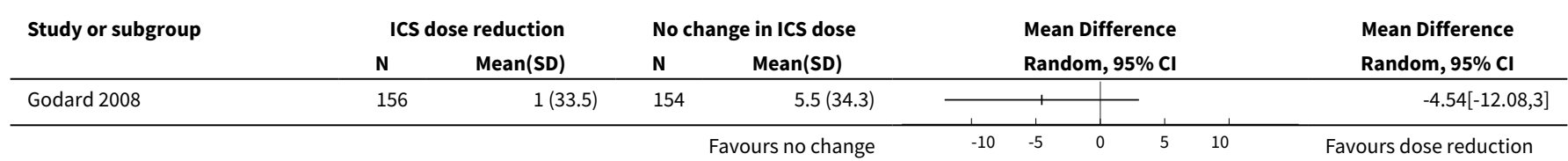


Analysis 2.8. Comparison 2 ICS dose reduction versus no change in ICS dose (concomitant LABA), Outcome 8 Lung function, reduction in $\mathrm{FEV}_{1}$ (\% predicted, change from baseline).

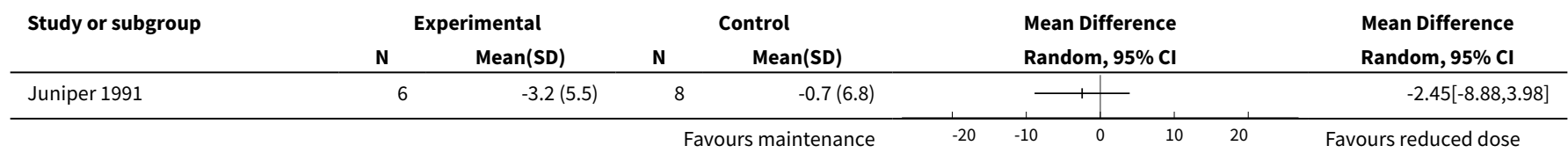

Analysis 2.9. Comparison 2 ICS dose reduction versus no change in ICS dose (concomitant LABA), Outcome 9 Exacerbation requiring hospitalisation.

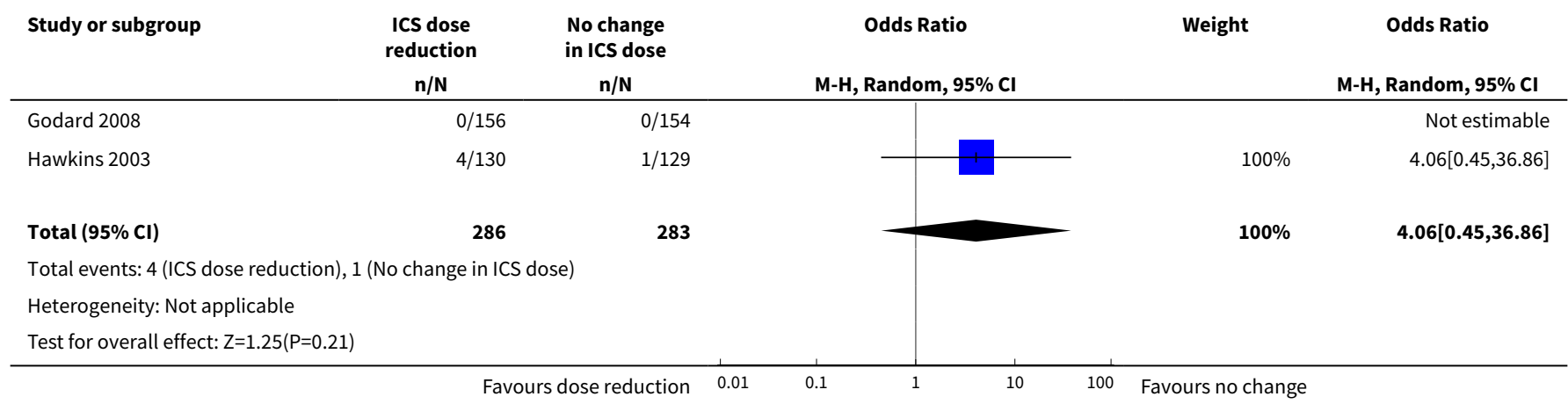

Analysis 2.10. Comparison 2 ICS dose reduction versus no change in ICS dose (concomitant LABA), Outcome 10 Exacerbation requiring ED visit.

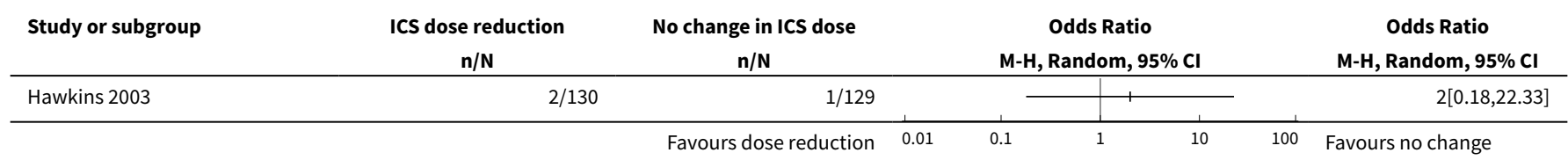

Analysis 2.11. Comparison 2 ICS dose reduction versus no change in ICS dose (concomitant LABA), Outcome 11 Mortality.

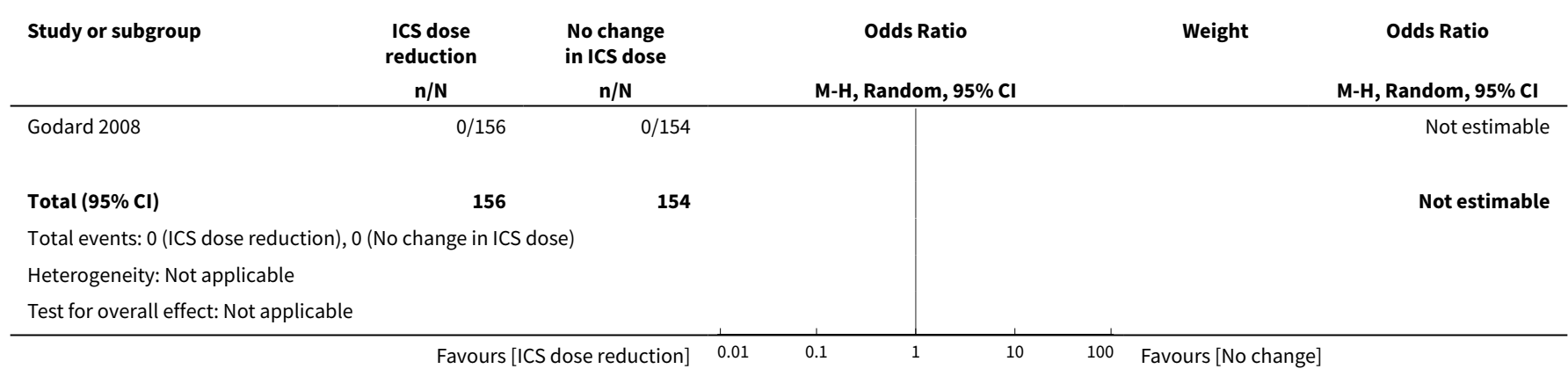




\section{APPENDICES}

\section{Appendix 1. Sources and search methods for the Cochrane Airways Group Specialised Register}

\section{Electronic searches: core databases}

\begin{tabular}{ll}
\hline Database & Frequency of search \\
\hline CENTRAL (the Cochrane Library) & Monthly \\
\hline MEDLINE (Ovid) & Weekly \\
\hline Embase (Ovid) & Weekly \\
\hline PsycINFO (Ovid) & Monthly \\
\hline CINAHL (EBSCO) & Monthly \\
\hline AMED (EBSCO) & Monthly \\
\hline
\end{tabular}

\section{Handsearches: core respiratory conference abstracts}

\begin{tabular}{ll}
\hline Conference & Years searched \\
\hline American Academy of Allergy, Asthma and Immunology (AAAAI) & 2001 onwards \\
\hline American Thoracic Society (ATS) & 2001 onwards \\
\hline Asia Pacific Society of Respirology (APSR) & 2004 onwards \\
\hline British Thoracic Society Winter Meeting (BTS) & 2000 onwards \\
\hline Chest Meeting & 2003 onwards \\
\hline European Respiratory Society (ERS) & $1992,1994,2000$ onwards \\
\hline International Primary Care Respiratory Group Congress (IPCRG) & 2002 onwards \\
\hline Thoracic Society of Australia and New Zealand (TSANZ) & 1999 onwards \\
\hline
\end{tabular}

\section{MEDLINE search strategy used to identify trials for the Cochrane Airways Group Specialised Register}

\section{Asthma search}

1. exp Asthma/

2. asthma\$.mp.

3. (antiasthma\$ or anti-asthma\$).mp.

4. Respiratory Sounds/

5. wheez\$.mp. 
6. Bronchial Spasm/

7. bronchospas\$.mp.

8. (bronch\$ adj3 spasm\$).mp.

9. bronchoconstrict\$.mp.

10. exp Bronchoconstriction/

11. (bronch\$ adj3 constrict\$).mp.

12. Bronchial Hyperreactivity/

13. Respiratory Hypersensitivity/

14. ((bronchial\$ or respiratory or airway\$ or lung\$) adj3 (hypersensitiv\$ or hyperreactiv\$ or allerg\$ or insufficiency)).mp.

15. ((dust or mite\$) adj3 (allerg\$ or hypersensitiv\$)).mp.

16. or/1-15

\section{Filter to identify RCTs}

1. exp "clinical trial [publication type]"/

2. (randomised or randomised).ab,ti.

3. placebo.ab,ti.

4. dt.fs.

5. randomly.ab,ti.

6. trial.ab,ti.

7. groups.ab,ti.

8. or/1-7

9. Animals/

10. Humans/

11. 9 not (9 and 10)

12. 8 not 11

The MEDLINE strategy and the RCT filter are adapted to identify trials in other electronic databases.

Appendix 2. Search strategy to identify relevant trials from the Cochrane Airways Group Specialised Register \#1 AST:MISC1

\#2 MeSH DESCRIPTOR Asthma Explode All

\#3 asthma*:ti,ab

\#4 \#1 or \#2 or \#3

\#5 MeSH DESCRIPTOR Adrenal Cortex Hormones Explode All

\#6 (steroid* or corticosteroid* or glucocorticosteroid* or glucocorticoid $^{\star}$ or corticoid ${ }^{\star}$ ) AND (inhal*)

\#7 ICS:ti,ab,kw

\#8 beclomethasone or beclometasone

\#9 budesonide 
\#10 fluticasone

\#11 ciclesonide

\#12 mometasone

\#13 flunisolide

\#14 triamcinolone

$\# 15 \# 5$ or \#6 or \#7 or \#8 or \#9 or \#10 or \#11 or \#12 or \#13 or \#14

\#16 step* NEAR3 down*

\#17 (reduc $^{\star}$ or decreas ${ }^{\star}$ ) NEAR3 (dose or treatment $^{\star}$ or therap ${ }^{\star}$ )

\#18 down ${ }^{\star}$ NEAR3 titrat $^{*}$

\#19 MeSH DESCRIPTOR Drug Administration Schedule Explode All

\#20 \#16 or \#17 or \#18 or \#19

\#21 \#4 AND \#15 AND \#20

[Note: in search line \#1, MISC1 denotes the field in which the reference has been coded for condition, in this case, asthma.]

\section{CONTRIBUTIONS OF AUTHORS}

All review authors contributed to drafting of the protocol, reviewed it critically for intellectual content, provided final approval of the version to be published and are accountable for all aspects of the work.

\section{DECLARATIONS OF INTEREST}

lain Crossingham: none.

Paul Marsden: received lecture fees and conference accommodation/fees from industry unrelated to the current review.

Nathan Halcovitch: none.

David Evans: provides freelance writing services to medical communication agencies.

\section{SOURCES OF SUPPORT}

\section{Internal sources}

- The authors declare that no funding was received for this systematic review, Other.

\section{External sources}

- IC, PM and NH declare that no funding was received for this systematic review, Other.

- DE: National Institute for Health Research, UK.

Evidence to guide care in adults and children with asthma, 13/89/14

\section{DIFFERENCES BETWEEN PROTOCOL AND REVIEW}

We used the mean difference instead of the standardised mean difference, as a combination of different scales would make clinical interpretation of the effect measure difficult.

\section{INDEX TERMS}

\section{Medical Subject Headings (MeSH)}

Adrenal Cortex Hormones [ ${ }^{*}$ administration \& dosage] [adverse effects]; Anti-Asthmatic Agents [*administration \& dosage] [adverse effects]; Asthma [ ${ }^{\star}$ drug therapy]; Forced Expiratory Volume; Quality of Life; Randomized Controlled Trials as Topic 


\section{MeSH check words}

Adolescent; Adult; Aged; Aged, 80 and over; Humans; Middle Aged 